\title{
Nanocomposite Coatings: Preparation, Characterization, Properties, and Applications
}

\author{
Phuong Nguyen-Tri $\mathbb{D}^{1},{ }^{1}$ Tuan Anh Nguyen $\mathbb{D}^{2},{ }^{2}$ Pascal Carriere, ${ }^{3}$ and Cuong Ngo Xuan ${ }^{4}$ \\ ${ }^{1}$ Department of Chemistry, University of Montréal, Montréal, QC, Canada \\ ${ }^{2}$ Institute for Tropical Technology, Vietnam Academy of Science and Technology, Hanoi, Vietnam \\ ${ }^{3}$ Laboratoire MAPIEM (EA 4323), Matériaux Polymères Interfaces Environnement Marin, Université de Toulon, Toulon, France \\ ${ }^{4}$ National Key Laboratory for Welding and Surface Treatment Technologies, National Research Institute of Mechanical Engineering, \\ Hanoi, Vietnam \\ Correspondence should be addressed to Phuong Nguyen-Tri; phuong.nguyen.tri@umontreal.ca
}

Received 9 September 2017; Revised 12 December 2017; Accepted 15 January 2018; Published 13 February 2018

Academic Editor: Omar S. Es-Said

Copyright (C) 2018 Phuong Nguyen-Tri et al. This is an open access article distributed under the Creative Commons Attribution License, which permits unrestricted use, distribution, and reproduction in any medium, provided the original work is properly cited.

\begin{abstract}
Incorporation of nanofillers into the organic coatings might enhance their barrier performance, by decreasing the porosity and zigzagging the diffusion path for deleterious species. Thus, the coatings containing nanofillers are expected to have significant barrier properties for corrosion protection and reduce the trend for the coating to blister or delaminate. On the other hand, high hardness could be obtained for metallic coatings by producing the hard nanocrystalline phases within a metallic matrix. This article presents a review on recent development of nanocomposite coatings, providing an overview of nanocomposite coatings in various aspects dealing with the classification, preparative method, the nanocomposite coating properties, and characterization methods. It covers potential applications in areas such as the anticorrosion, antiwear, superhydrophobic area, self-cleaning, antifouling/antibacterial area, and electronics. Finally, conclusion and future trends will be also reported.
\end{abstract}

\section{Introduction}

1.1. Definition. A nanocomposite coating is a material composed of at least two immiscible phases, separated from one another by interface region. The material must contain the nanometer scale in at least one dimension in which the major component is called matrix in which fillers are dispersed [1].

1.2. Classification. The classification of nanocomposite coatings is based on various methods dealing with (i) type of nanostructured fillers or (ii) type of matrix where filler nanostructures are dispersed.

1.2.1. Type of Nanostructured Fillers. There are 3 main groups of nanocomposite coating as follows [1]:

(i) 0D nanocomposite coatings: the filler are nanoparticles (3 dimensions in nanometer scale).

(ii) 1D nanocomposite coatings: the filler are nanotubes or whiskers (2 dimensions in nanometer scale). (iii) 2D nanocomposite coatings: the filler are nanolayers (1 dimension in nanometer scale).

1.2.2. Type of Matrix. Tow types of matrix which are organic and inorganic matrix can be found. Thus, there are 4 main groups of nanocomposite coating as follows (matrix/ nanofiller):

(i) Organic/inorganic nanocomposite coatings (O/I nanocomposite coatings)

(ii) Organic/organic nanocomposite coatings $(\mathrm{O} / \mathrm{O}$ nanocomposite coatings)

(iii) Inorganic/organic nanocomposite coatings (I/O nanocomposite coatings)

(iv) Inorganic/inorganic nanocomposite coatings (I/I nanocomposite coatings). 


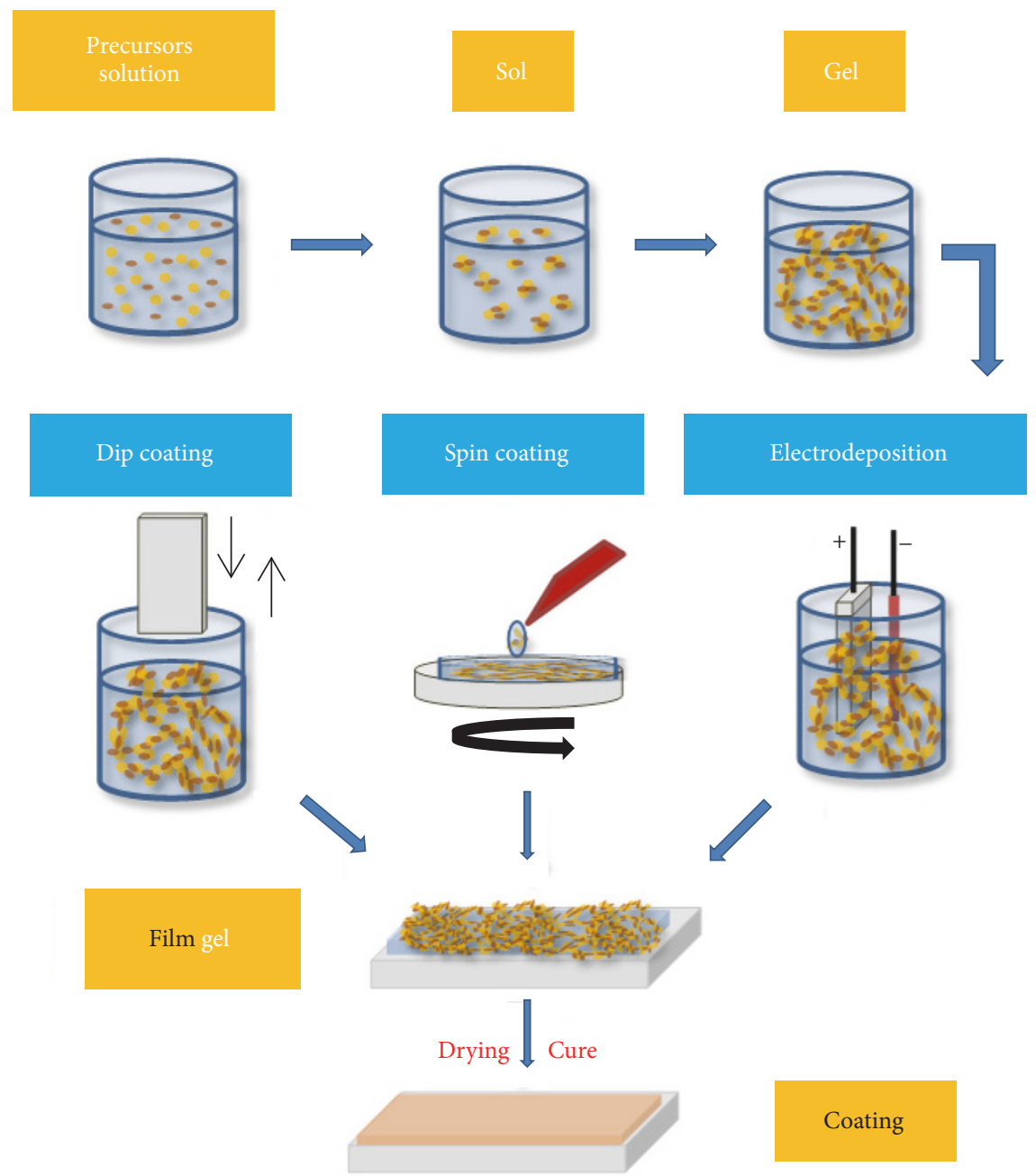

Figure 1: Preparation of coatings by sol-gel method [85].

\subsection{Materials}

1.3.1. Materials for Matrix. For organic matrix, called polymer-based nanocomposite, the most used polymers for preparation of nanocomposite coating can be listed as follows: epoxy [2-7], polyurethane [8,9], Chitosan [10, 11], polyethylene glycol (PEG) [12-15], polyvinylidene fluoride (PVDF) [16], PANi [17-19], PPy [20-23], polystyrene [24], polyamic acid and polyimide [25], rubber-modified polybenzoxazine (PBZ) [26], polymers containing reactive trimethoxysilyl (TMOS) [27], pullulan [28], fluoroacrylic polymer [29, 30], ethylene tetrafluoroethylene (ETFE) [31], polyacrylate [3], poly(N-vinyl carbazole) [32], polycarbonate [33], fluorinated polysiloxane [34], polyester [35], polyacrylic [36], polyvinyl alcohol (PVA) [37], polydimethylsiloxane [38], polyamide [39], and UV-curable polymers [40].

For inorganic matrix, such as metal matrix or alloy matrix, these nanocomposite coatings could be prepared by various methods, including chemical vapor deposition (CVD) (see Figure 3), powder metallurgy, physical vapor deposition (PVD) [41-45], thermal plasma spray [46-48], sol-gel [49-52] (see Figure 1), epitaxial growth [53], cold spray
[54-61] (see Figure 2), and electrodeposition [62-67]. Metal matrix composite coatings that dispersed a second phase $[68,69]$ have attracted extensive attention owing to unique properties such as oxidation and corrosion resistance $[69,70]$, wear resistance [71, 72], and magnetic properties [72].

1.3.2. Materials for Nanofillers. For inorganic nanofillers, the types of nanoparticles are carbides [58], nitrites [59-61,73-77], borides [55], oxides [4, 5, 62, 65], metallic particles $[17,78]$, clay $[4,5,35]$, CNT [54], and nanodiamond $[56,79]$. For organic nanoparticles (organic nanofiller), the most used nanoparticles were PTFE [80-82], PEO [83], PANi [31], or nanocellulose and cellulose nanocrystal [18, 40].

\section{Preparative Methods}

2.1. Sol-Gel Method. The sol-gel method is suitable to obtain high quality films up to micron thickness and is a complementary of the physical deposition techniques. However, there are limits of sol-gel application to coating on the metallic subtracts. This method exhibits several drawbacks involving crackability and thickness limits. Sometimes also 


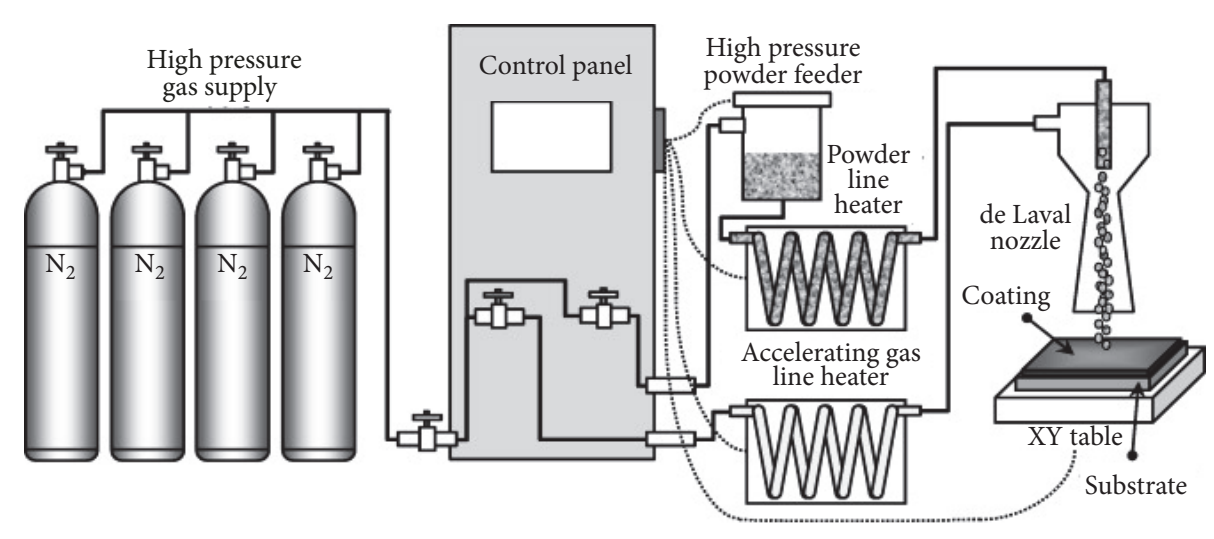

FIGURE 2: Principle of cold spray technique for preparation of nanocomposite [86].

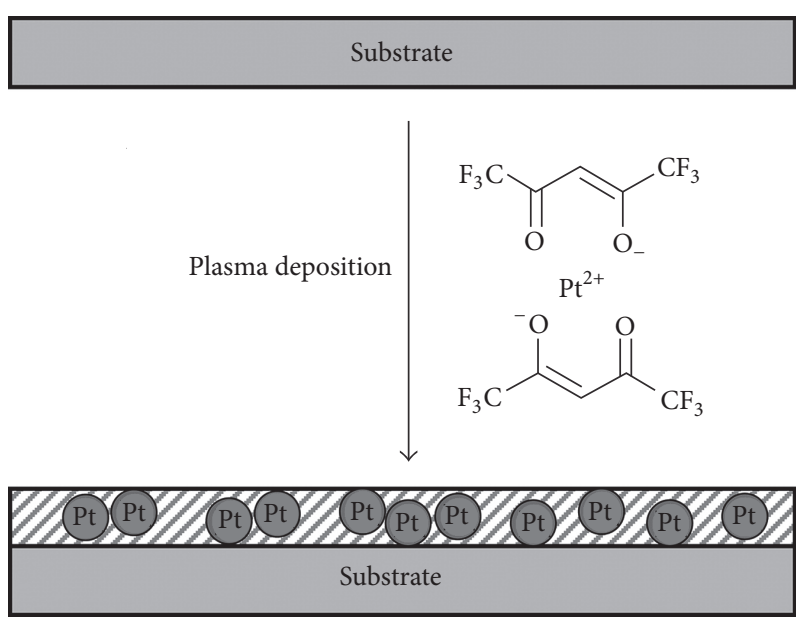

FIgURE 3: Plasma enhanced chemical vapor deposition [91].

the thermal treatment may be critical. Tensile stresses develop during drying and can lead to crack formation if the film is thicker than a critical value.

In case of inorganic matrix, the second phase can be added to sol-gel for inorganic nanofillers, such as the I/I coatings [49-52]. In the case of organic matrix, a wellknown approach to generate inorganic nanophases within an organic matrix is to utilize sol-gel chemistry [18]. Inorganic sol-gel precursors such as silicon, titanium, aluminum, and zirconium metal alkoxides are employed in the formulation of nanocomposite coatings. A wide range of oligomers as well as low molecular weight organic compounds are often reported to be used as organic phase precursors. Under controlled conditions, silanes and organic molecules can form coatings containing silica nanoparticles or nanophases. In the presence of a coupling agent, the organic and inorganic phases can be covalently linked. Silica nanofiber formation in a system containing TEOS, methacryloxypropyltrimethoxysilane (MAPTMS), a urethane acrylate resin, and an acrylated phenylphosphine oxide oligomer (APPO) has been reported [40].
The nanofibers were shown to improve the mechanical properties of the organic matrix. By this sol-gel process, Facio and Mosquera [38] also successfully fabricated the nanocomposite coatings containing (i) a mixture of monomeric and oligomeric ethoxysilanes, (ii) a hydroxyl-terminated polydimethylsiloxane, (iii) colloidal silica particles, and (iv) a surfactant (n-octylamine). In addition, the sol-gel method could be used in combination with the electrodeposition for incorporation of inorganic nanofillers into the organic matrix [78] or into inorganic matrix [84].

2.2. Cold Spray Method. Unlike the traditional thermal spray (gas-flame, plasma, and detonation spraying), cold spraying allows fabrication of coatings at the lower temperatures than melting points of the sprayed materials. Cold spray technique was conducted at low temperatures, so this method avoids the deterioration phenomenon of the materials such as oxidation and decomposition as well as phase transition during the process. The obtained coatings have low porosity $(<1 \%)$ and low oxygen concentration. In addition, the coatings have high strength (>280 MPa) and strong adhesion $(>70 \mathrm{MPa})$.

This method is used to produce the nanocomposite coating, which has metallic matrix, such as $\mathrm{Cu}[54,55], \mathrm{Al}$ $[56,57]$, Co [58], or alloy matrix [59-61], and its nanofillers are nitrite, carbide, boride, diamond, CNT, or others [54-61]. To fabricate the nanocomposite powders for this cold spray method, the mechanical alloying (MA) should be used with metallic matrix powders and other nanoparticles.

2.3. CVD Method. This method usually used for the fabricating of the I/I nanocomposite coatings, which include the inorganic matrix and inorganic nanofillers [87-89]. In order to improve the quality of coating, the aerosol-assisted CVD method can be used [90].

On the other hand, the $\mathrm{O} / \mathrm{I}$ nanocomposite coatings were also successfully fabricated by using CVD method with platinum (II) hexafluoroacetylacetonate as precursors [91]. This process allows producing a layer of nanocomposite on the organic substrate by a single step which displays both ionic and electric conductivities. The distinct advantages of this method are related to its high quality films and 


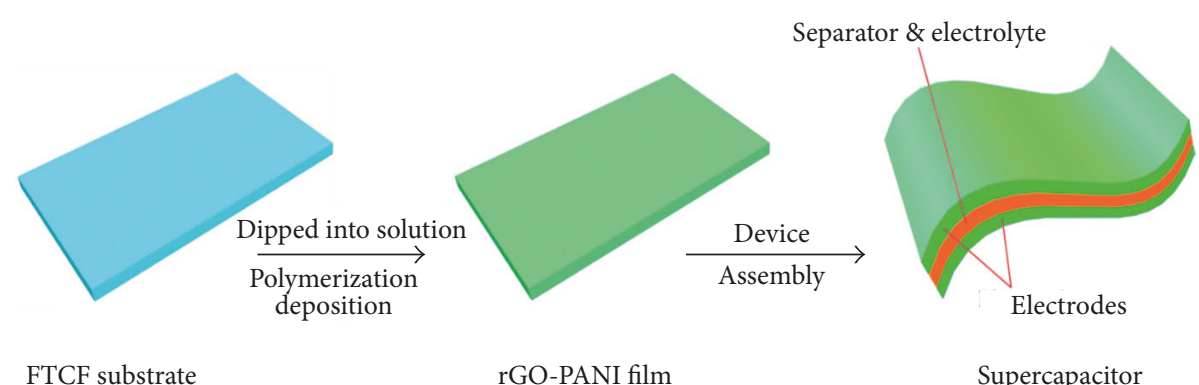

FIGURE 4: Preparation of nanocomposite coating via in situ polymerization method [105].

its facility for any kind of complex subtracts with a good reproductivity.

2.4. PVD Method. This method is used generally for producing of the I/I nanocomposite coating [41-45, 92-97], which includes the inorganic matrices and inorganic nanoparticles. For these coatings, PVD method includes the following: laser ablation [98], thermal evaporation [99], ion beam deposition [100], ion implantation [101, 102], laser-assisted deposition [103], and atom beam cosputtering technique. In case of O/I nanocomposite coatings, Schild [104] has successfully fabricated the nanocomposite coating with organic matrix, by using the aerosol-assisted plasma deposition.

2.5. Thermal Spray Method. This method is often used to make nanocomposite coatings with a matrix of metal or alloy. The spray material is a nanosized alloy powder (formed by ball milling [48]) and dispersed in a suspension solution using suspensions (Thermally Sprayed [47] and Suspension Plasma Spray Process [46]) to conduct plasma thermal spraying.

2.6. In Situ Polymerization Method. This method was used to fabricate the nanocomposite coatings with organic matrices, which were conducting polymer $[17,18]$ or other monomers with initiators. The nanofillers were metals or metal oxides (see Figure 7). The polymerization takes place by using electric power (electrodeposition) [19], oxidizing agents [17, $18,105]$, or photon (photopolymerized) $[40,106,107]$. The similar methods are emulsion polymerization $[108,109]$ or latex emulsions [110] for organic matrices (see Figure 4).

2.7. Electroless Deposition. This method is usually applied for producing the nanocomposite coatings with Niken matrix and nanofillers are carbide, nitrite, boride, or PTFE $[49,81,82,111-117]$. In order to improve the hardness, anticorrosion, and antiwear of coating, the thermal posttreatment at $500-700^{\circ} \mathrm{C}$ should be applied.

2.8. Electrodeposition Method. This method could be used for the fabrication of nanocomposite coatings, which contain organic nanofillers (such as PEO, PTFE [80, 83, 118]) or inorganic matrices [119-123] or organic matrices [19, 22, 32, $78,124]$.

In the case of organic matrices, the electrochemical codeposition of nanocomposites has been reported by many researchers [123-141]. Zhitomirsky had reviewed the various nanostructured organic-inorganic coatings using electrophoretic deposition [140]. The author summarized various organic matrices, such as polyelectrolytes, poly(ethylene imine), which were electrochemically codeposited with metal ions as well as with ceramic nanoparticles. The electrochemical codeposition of carbon nanotubes/conducting polymers has also been reported [126-129, 131, 134]. Other studies involved the electrochemical codeposition of oxide and metal nanoparticles, such as $\mathrm{Ni}$ (as matrix) and $\mathrm{Al}_{2} \mathrm{O}_{3}$ (as nanofiller) $[130,136]$. Chitosan was also reported as a dominant organic matrix, used for the electrodeposition of nanocomposite coatings [125, 132, 133].

In the case of inorganic matrices, the electrodeposition of nanocomposite coatings can be performed by using the direct current (DC), pulsed current (PC), and pulsed reverse current (PRC) methods [144]. Among these 3 methods, the PC method provides more control on structure and properties of the coatings; thus the obtained coatings had better tribologic and corrosion properties than ones made by DC method [145]. On the other hand, compared with other methods, the electrodeposition technique was much easier in terms of manufacturing processes and lower cost [62]. The main advantages of this technique are related to the uniform distribution of particles, the ability of continuous processing and the reduction of waste materials [63]. Compared to conventional coatings, nanocomposite coatings exhibit higher hardness and heat resistance due to the presence of nanoparticles in the grain boundaries, which can prevent the dislocations movement and recrystallization at high temperature [64]. As a strong and tough metal, Nickel has been widely used as an electrodeposited metal matrix, in combining with nanofillers such as boron nitride $[66,67]$ and $\mathrm{Al}_{2} \mathrm{O}_{3}$ nanoparticles $[62,65]$. Some authors reported that the changing duty cycle and frequency during pulsed electrodeposition can also produce nanocomposite coatings [146].

2.9. Solution Dispersion. This method is mainly applied for the preparation of polymer nanocomposite coatings $[4,5$, $7,28]$, reinforced with nanofillers such as metal oxides, nanoclay, and carbon nanotube (CNT). In this method, beside the use of traditional magnetic/mechanical stirring methods, the ultrasound-assisted (sonication) stirring [4, 5, 28 ] was used for better dispersion of nanofillers into polymer matrices. 
2.10. Spray Coating and Spin Coating Methods. These methods are widely used for the preparation of polymer nanocomposite coatings. In the case of spray coating, by using the atomizer, the nanocomposite coatings had better properties $[8,29]$. The atomizer could also be used for thermal spray method, for example, atomized spray plasma deposition [147]. In the case of spin coatings $[16,148]$, it provides uniform thin films to flat substrates. The substrate is rotated at high speed in order to spread the coating materials by centrifugal force. This method is suitable for the preparation of thin-film nanocomposite coatings.

2.11. Dip Coating. This technique is widely used in industry; the dip coating technique consists in soaking a substrate in a solution of nanocomposite and pulled up at a constant and controlled speed. The substrates are then covered with nanocomposite as it is removed from the solution. Due to the imposed pulled up rate, the amount of nanocomposite on the substrate surface is also controlled.

There are two pulled out rates of the substrate, which have direct effect on the thickness of the film. At low pulled up rates, there is the capillary regime where the rate of evaporation of the solvent is greater than that of the shrinkage of the plate. This means that the shorter the shrinking speed, the thicker the film. At high pulled up rates, the trend is reversed. In this so-called drainage regime, it is the combination of the adhesion of the solution to the substrate and the gravity that forces the drainage of the solution (Figure 6). This causes thickening of the films as the shrinkage rate increases.

The advantage of this technique is that the preparation of a flat surface is therefore suitable for all forms of coated substrates. The fact that the solution can be reused until evaporation or depletion of the solute also makes this technique particularly convenient, especially for industrial applications.

2.12. Other Preparative Methods. There are also several other methods for the elaboration of nanocomposite coatings but they are less popular such as the following: self-assembly (O/I coatings [46]); layer-by-layer assembly (O/O coatings [157]); localized laser heating, solid-state displacement reactions, ball impact deposition (for I/I coatings [158-160], resp.); and atomic layer deposition (for I/O coatings [161-163]).

\section{Characterization and Properties}

3.1. Effect of Nanofillers on the Microstructure and Morphology of Coatings. In case of organic matrices, the appropriated dispersion of the nanofillers is crucial to obtain final desired properties. The small size of the nanoparticles exhibits some advantages since it enables penetrating into ultrasmall holes, indentation, and capillary areas in the polymer matrix. For example, the incorporation of nanoparticles into epoxy resins showed an enhancing of the integrity and durability of coatings thanks to the filling up of microcavities and cracks in the coatings [164-167]. Nanoparticles can also prevent disaggregation of the polymer during curing, leading to a homogenous coating. In a recent study, it was recognized that nanoparticles with a higher specific surface area not only exhibit an increase of the distribution of nanofillers in the epoxy matrix but also enhance epoxy-curing process $[4,5]$. For polyester coatings, Golgoon et al. [35] reported that the embedding nanoclay created a denser coating and more uniform and less pores in comparison with the pure polyester coating. The presence of nanofiller cans also perturb the crystallization of polymer. In many case, nanofillers enhance the crystallinity degree and reduce the spherulites file of semicrystallinity polymers.

In the case of inorganic matrices, the formation of nanocomposite structures is connected with a segregation of the one phase to grain boundaries of the second phase, and this effect is responsible for stopping of the grain growth [79]. Li et al. [118] reported that the presence of nanoparticles (anatase and rutile nano- $\mathrm{TiO}_{2}$ ) reduced the grain size of the nickel matrix. For conventional materials, size of grain of monocrystals varies from about $100 \mathrm{~nm}$ to several hundred millimetres. In this case, the number of atoms in grains is much greater than that in boundary regions. For nanocrystalline materials, the grain size is about $10 \mathrm{~nm}$ or less [79]. By adding nanocrystal phase into the metal matrix, the volume fraction of grain boundaries might increase. Mitterer et al. [153] formed nitride nanocrystalline phases within a metal matrix, such as $\mathrm{TiN}$ in $\mathrm{Ni}$ [73], $\mathrm{ZrN}$ in $\mathrm{Ni}$ [74], $\mathrm{ZrN}$ in $\mathrm{Cu}$ $[75,76]$, and $\mathrm{CrN}$ in $\mathrm{Cu}$ [77]. In these coatings, one metal may be converted into nitride in the nanocrystalline phase and the other may be transported into the growing film unreacted. On the other hand, thermal posttreatment has strong effect not only on the grain size $[50,59]$, crystallization [154], and morphology [168] but also on the dislocation density and the interactions between nanoparticles and the matrix [46] or the bonding of microstructural phases [47].

\subsection{Effect of Nanofillers on the Mechanical Properties of Coatings}

3.2.1. Tensile and Impact Properties. In case of organic matrices, the incorporation of nanoparticles into the epoxy coating enhanced significantly the impact strength of the epoxy coating $[4,5]$. The epoxy coating modified with $\mathrm{TiO}_{2}$ nanoparticles showed the best enhanced impact strength of all the epoxy coatings. The distinct improvement in their stiffness may be ascribed to the following two mechanisms: (i) the nanoparticles occupy pinholes and voids in the thinfilm coating and reinforced interconnected matrix, causing a reduction of total free volume and an enhancement of the cross-linking density of the cured epoxy. As such, the cured nanocomposite coating has reduced chain segmental motions and improved stiffness. (ii) Nanoparticles may act to prevent epoxy disaggregation. By using the nanoindentation method for these epoxy nanocomposites [32], it was found that modification with nanoparticles did not always enhance the stiffness of the epoxy coatings. The presence of nano- $\mathrm{SiO}_{2}$ in epoxy coatings increased Young's modulus up to 20 times, whereas nanoclay and nano- $\mathrm{Fe}_{2} \mathrm{O}_{3}$ modified samples showed $\sim 30 \%$ and $\sim 25 \%$ decrease, relative to the unmodified epoxy coating, respectively. It was realized that, based on Young's modulus of the nanocomposite coatings, its stiffness depended heavily upon the integrity and internal 

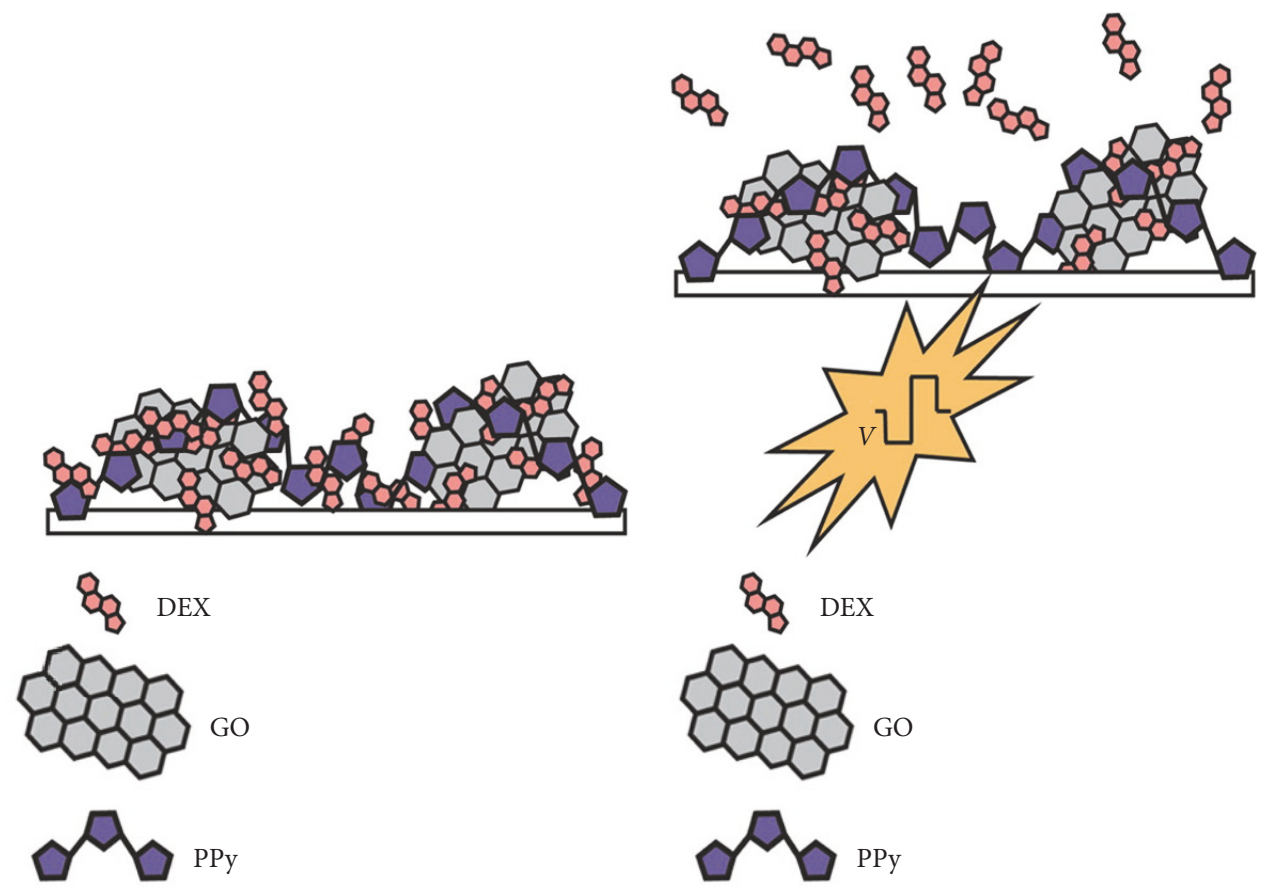

(a)

(b)

FIGURE 5: Schematic representation of the (a) GO/PPy-DEX nanocomposite and (b) DEX release from the GO/PPy nanocomposite in response to electrical stimulation [124].

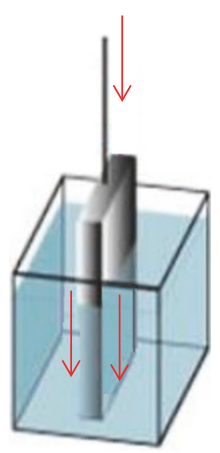

(a)

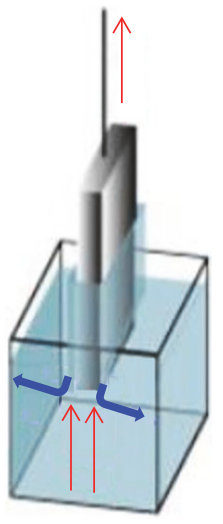

(b)

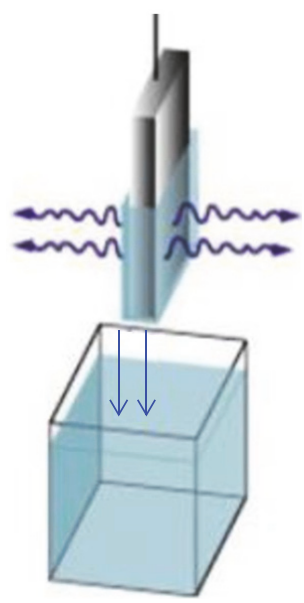

(c)

FIGURE 6: The dip coating: (a) submersion of the substrate in the nanocomposite solution, (b) withdrawing at constant speed of the substrate covered with nanocomposite, and (c) evaporation of the solvents.

properties of the coating surface, as under mechanical stress the microvoids between the nanoparticles or between the polymer matrix and the nanoparticles may become the origin of cracks. Ragosta et al. [169] reported that the addition of nano- $\mathrm{SiO}_{2}$ up to $10 \mathrm{wt}$ \% brought a significant enhancement in fracture toughness and an increase in the critical crack length for the onset of crack propagation. In the case of inorganic matrices, the presence of nanograins in the amorphous matrix improved the protection against impacts of high speed microparticles [2].
3.2.2. Hardness. For traditional organic and inorganic coatings, the measurement of microhardness can be used for evaluation of hardness. However, for the nanocomposite coatings, in order to study the effect of nanoparticles on the hardness of coatings, AFM based nanoindentation is found to be more appropriate $[4,56]$, with the size of AFM tip being about $50 \mathrm{~nm}$. An extra result can be obtained from this nanoindentation is Young's modulus of coating [4]. 


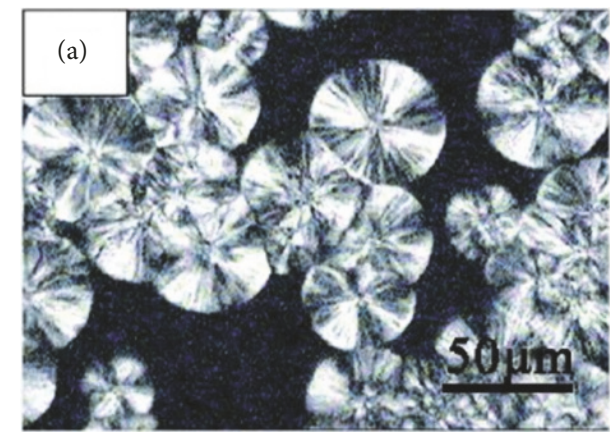

(a)

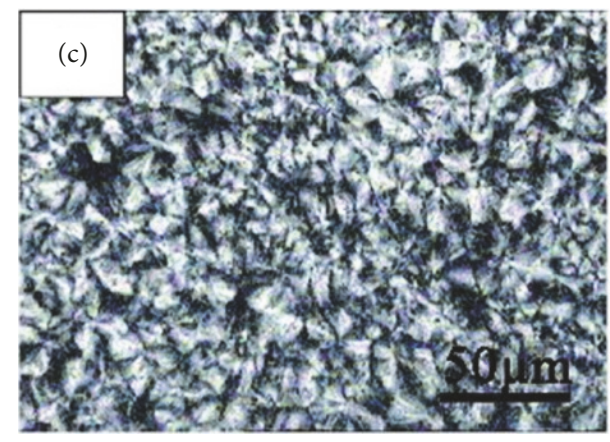

(c)

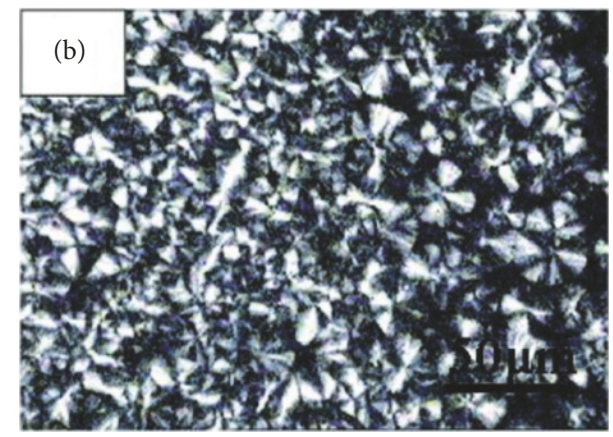

(b)

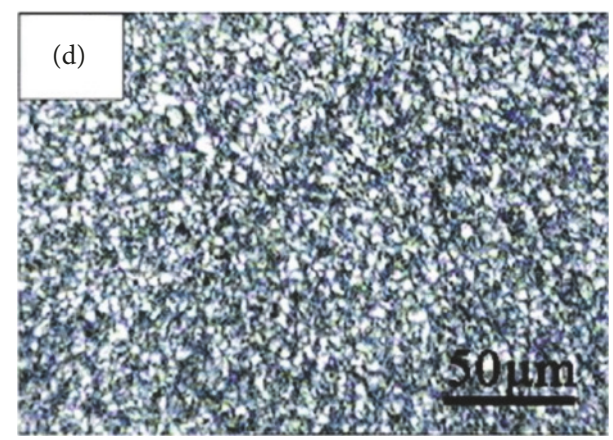

(d)

Figure 7: Optical micrographs of neat PLA and PLA/MOF (metal oxide framework) composites: (a) PLA, (b) PM0.5, (c) PM1, and (d) PM1.5.

(a) Organic Matrices. The addition of solid particles to polymers to improve their mechanical properties is a very common method. These are generally ceramic particles such as $\mathrm{SiO}_{2}, \mathrm{Al}_{2} \mathrm{O}_{3}, \mathrm{ZnO}, \mathrm{TiO}_{2}$, and $\mathrm{CaCO}_{3}$. Among them nano$\mathrm{SiO}_{2}$ is the most used and studied particle. Sung et al. [9] studied the effects of nanoalumina addition on the scratch behavior of polyurethane coatings. They concluded that the addition of hard particles did not reduce scratch damage as assessed by scratch width measurement. For polyacrylic coating, Sajjadi et al. [36] reported that its scratch resistance is improved by the addition of nanoalumina particles, but it is not greatly changed by the addition of nanodiamond particles. Behler et al. [39] studied the effect of nanodiamond addition to polyacrylonitrile and polyamide (80 wt.\% and 40 wt.\%) on their modulus and hardness by the nanoindentation test. They observed that the addition of nanodiamond to the matrix could dramatically increase its hardness $(\sim 2$ times). Maitra et al. [170] produced dilute nanocomposites (0.6 wt.\%) of polyvinyl alcohol matrix reinforced with nanodiamond and observed that the addition of the particles could greatly improve hardness (up to $80 \%$ ) of the polymeric matrix.

(b) Inorganic Matrices. Based on the value of hardness, the inorganic coatings can divide into two groups: (i) hard coatings (hardness < $40 \mathrm{GPa}$ ) and (ii) superhard coatings (hardness > $40 \mathrm{GPa}$ ). Among the various hard materials, there are only a few superhard materials, that is, cubic boron nitride (c-BN), amorphous diamond-like carbon (DLC), amorphous carbon nitride $(\mathrm{a}-\mathrm{CNx})$, and poly-crystalline diamond [79]. For metallic nanocomposite coatings, in order to obtain superhardness, normally the plastic deformation should be prohibited; the dislocation movement and grain boundary sliding should also be prevented. Nowadays, researchers believed that the grain boundary diffusion and grain boundary sliding would be needful to improve toughness of nanocomposite coatings. Thus there are two ways for fabrication of the superhard and high toughness nanocomposites [171], as follows.

First, by the combination of two or more nanocrystalline phases, the complex boundaries could be created, then accommodating the coherent strain, thus increasing the hardness of coating. In this direction, Mitterer et al. [153] elaborated hard nanocrystalline phases within a metal matrix. The hardness of these coating systems varied from 35 to approximately $60 \mathrm{GPa}$. The higher hardness of solid compounds could be obtained by forming high strength grain boundaries, where there was a wide miscibility gap with a certain chemical affinity to each other. In this case, both mechanism modes of dislocation and grain boundary may contribute to the hardness of coatings [172-174], while the metallic matrix could guarantee their toughness.

The second way is to embed nanocrystalline phases in an amorphous phase matrix $[87,93,168]$. In this direction, the promising candidates for the amorphous matrix are the diamond-like carbon (DLC), amorphous carbon nitride, or other hard amorphous materials. Whereas the nanosized nitrides, such as $\mathrm{TiN}, \mathrm{Si}_{3} \mathrm{~N}_{4}, \mathrm{AlN}$, and $\mathrm{BN}$, could be used as strengthening phases. By embedding nanocrystalline $\mathrm{TiC}$ in DLC matrix, Voevodin et al. [103, 154] obtained the hardness of $32 \mathrm{GPa}$ for this nanocomposite coating. Vepřek et al. $[155,156]$ also embedded the TiN nanocrystals (4-11 nm) 
in amorphous $\mathrm{Si}_{3} \mathrm{~N}_{4}$ matrix and obtained its hardness of 50-70 GPa. Similarly, Zhang et al. [93] prepared a coating with a hardness of about $40 \mathrm{GPa}$ by embedding TiCrCN nanocrystalline $(8-15 \mathrm{~nm})$ in an amorphous DLC matrix.

In another direction, in case of Ni-P electroless coatings, incorporation of other nanoparticles, such as CNT [111, 112], nano-SiO ${ }_{2}[113,114]$, nano-SiC $[175,176]$, nano-WC [115], and nano- $\mathrm{Al}_{2} \mathrm{O}_{3}[116]$, increased their hardness. The hardness of all these nanocomposite coatings also increased after thermal posttreatment at $400^{\circ} \mathrm{C}$ during $1 \mathrm{~h}$. Similar result was obtained for the thermal sprayed coatings [47]. Ali et al. [47] reported that the thermal posttreatment allows increasing hardness of WC-12 wt.\% Co nanocomposite coatings by crystallization and improving the bonding of microstructural phases.

3.3. Effect of Nanofillers on Thermal Property of Coating. In the case of organic matrices, generally the incorporation of nanometer-sized inorganic particles into the polymer matrix can enhance thermal stability by acting as a superior insulator and mass transport barrier to the volatile products, generated during decomposition [177]. Adding the nanoparticles into polymer matrix modifies its glass transition temperature $\left(T_{g}\right)$. An increase in $T_{g}$ has been reported in few cases for polystyrene and other polymers [178-180], whereas few other reports have demonstrated a reduction of $T_{g}$ when nanofillers were added to polymers, such as the alumina/poly(methyl mathacrylate) (PMMA) nanocomposites [181]. Therefore, the relationship between the interaction mechanism and $T_{g}$ is still an open question. In a recent research [5], the DSC tests revealed that all of the epoxy nanocomposite coatings, except the one modified with the $\mathrm{Fe}_{2} \mathrm{O}_{3}$ nanoparticles, showed an increased glass transition temperature value. The incorporation of nano- $\mathrm{TiO}_{2}$ led to an increase of the $T_{g}$ value of the epoxy coatings from $58^{\circ} \mathrm{C}$ to even $170^{\circ} \mathrm{C}$. The TGA test also showed that, except for nano-ZnO, the thermal stability of the modified epoxy nanocomposites was not superior to that of the neat epoxy resin at low temperature. During high temperature periods, nano- $\mathrm{SiO}_{2}$, nano- $\mathrm{Fe}_{2} \mathrm{O}_{3}$, and nano- $\mathrm{ZnO}$ enhanced the thermal stability of the epoxy matrix. Among the epoxy nanocomposites, the one modified by nano- $\mathrm{ZnO}$ showed the best thermal stability. By using DSC and DMTA, Zabihi et al. [182] also found that $\mathrm{Fe}_{2} \mathrm{O}_{3}$ nanoparticles improved the crosslink density of epoxy, as evidenced by the increase in the glass transition temperature. In case of inorganic matrices, for thermal sprayed coatings, the nanocomposite structure had higher thermal shock resistance than the conventional structure $[183,184]$.

\subsection{Effect of Nanofillers on the Anticorrosive and Antiwear} Properties of Coatings. In the case of organic matrices, it is reported that epoxy based coatings [4] containing metal oxides nanoparticles significantly improved the corrosion resistance of the coated steel, with the $\mathrm{Fe}_{2} \mathrm{O}_{3}$ and halloysite clay nanoparticles being the best. The EIS measurements indicated that the incorporation of nanoparticles increased the coating resistance and the charge transfer resistance while reducing the coating capacitance and the double layer capacitance. Zhang et al. [185] reported that incorporation of nano- $\mathrm{SiO}_{2}$ into epoxy reduced its friction and wear at low nanofiller content ( 2 vol\%). For polyester coatings, Golgoon et al. [35] reported that the embedding nanoclay led to the absence of pores and flaw in coatings, as well as creating a protective barrier against corrosive electrolytes penetration; thus the corrosion resistance of nanocomposite coatings was higher than the pure coatings. They also reported that, with the presence of nanoclay, the wear rate of nanocomposite coating was much lower than neat coating because of relatively denser structure in the presence of nanoparticles.

In the case of inorganic matrices, for $\mathrm{Ni}-\mathrm{P}$ electroless coatings, the incorporation of nanoparticles, such as nano$\mathrm{SiO}_{2}$ [186], nano- $\mathrm{Al}_{2} \mathrm{O}_{3}[116,117,187]$, nano- $\mathrm{CeO}_{2}$ [188], and CNT [112], increased their anticorrosion in $\mathrm{NaCl}$ and $\mathrm{H}_{2} \mathrm{SO}_{4}$ solutions. The presence of nanoparticles in Ni-P matrix also reduced their wear rate, as reported for CNT [112], nano$\mathrm{Al}_{2} \mathrm{O}_{3}$ [116], and nano- $\mathrm{SiO}_{2}[113,114]$. For electrodeposited coating, incorporation of hard $\mathrm{SiC}$ nanoparticles into metallic matrix led to having better corrosion resistance and excellent wear resistance [152, 189-193]. Similar results are also obtained for magnetron sputtered coatings. Wei et al. [194, 195] reported that the presence of metal carbides nanocrystallites in amorphous matrix exhibits the low-friction behavior within a wide load range. The presence of nano- $\mathrm{Al}_{2} \mathrm{O}_{3}$ in the $\mathrm{Ni}$ matrix also increased its anti-sand-wear performance for steel substrate [119].

3.5. Nanoparticles in Nonwetting Nanocomposite Coatings. Surfaces are considered as superhydrophobic when water contact angle (WCA) is greater than $150^{\circ}$. The use of superhydrophobic coatings to remove water on metal surfaces is gaining a lot of attention due to the special benefits of (i) self-cleaning surfaces, (ii) protection against freezing or snow (anti-icing) on the surface of the metal in the wintry winter weather, (iii) antifouling properties, (iv) barrier to atmospheric corrosion for metals in the marine environment, and (v) minimizing some of the unwanted effects on the surface of metals in outdoor conditions [196-200]. Depending on the type of material, various superhydrophobic coatings have been successfully developed in different scales. Manca et al. [196] reported self-cleaning and antiglare coating on glass plates using modified nanosilica particles with sol-gel technique.

He et al. [197] used myristic acid to successfully treat the hydrophobic surface for aluminum anodization, thereby improving corrosion resistance in seawater. Kako et al. [200] found that changes in surface morphology (from hydrophobic channels to superhydrophobic surfaces) could alter the ability to cling to or slip snow particles. Sarkar and Farzaneh [201] argued that ice shovels were removed from the surface of the superhydrophobic material, while that of ice deposited on bare aluminum surfaces was large at $369 \pm$ $89 \mathrm{kPa}$. Kulinich and Farzaneh $[202,203]$ also commented on similar results. Li et al. [204] have introduced hydrophobic polydimethylsiloxane (PDMS)/nanosilica overlays to reduce ice deposition. The authors found that both coatings exhibited super hydrophobicity, in terms of both multiscale and low surface energy. 

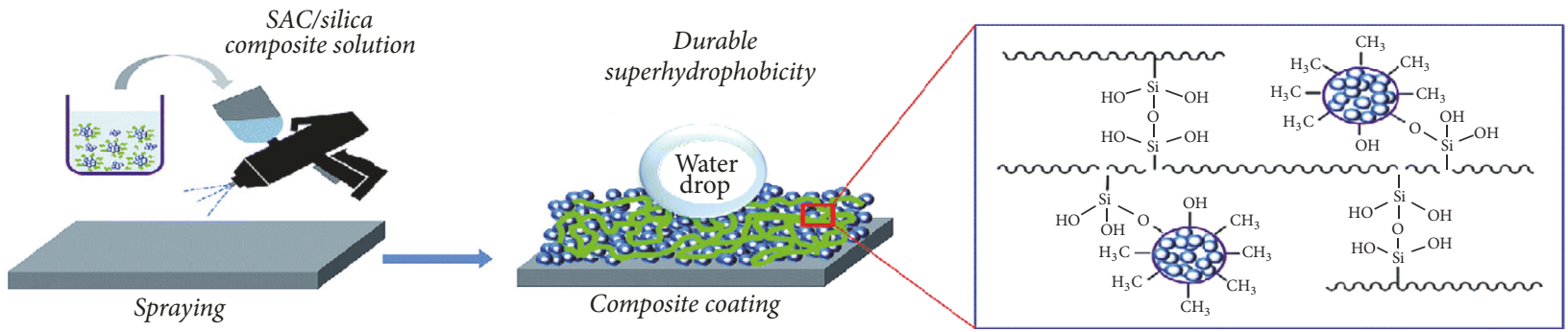

(a)

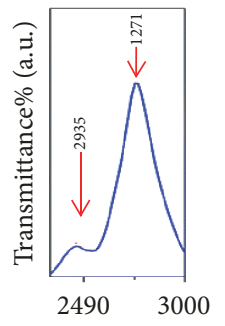

Wavenumber $\left(\mathrm{cm}^{-1}\right)$

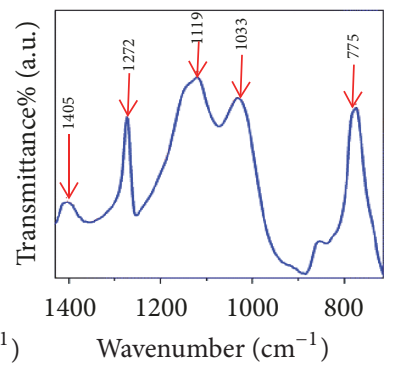

(b)

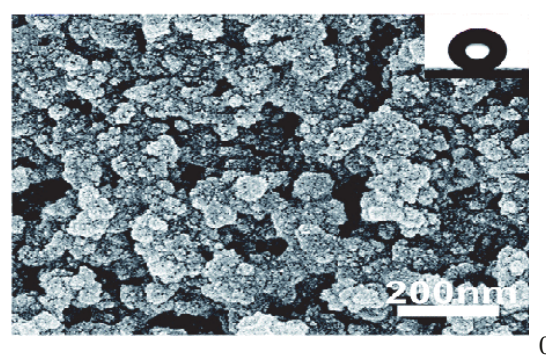

0.0

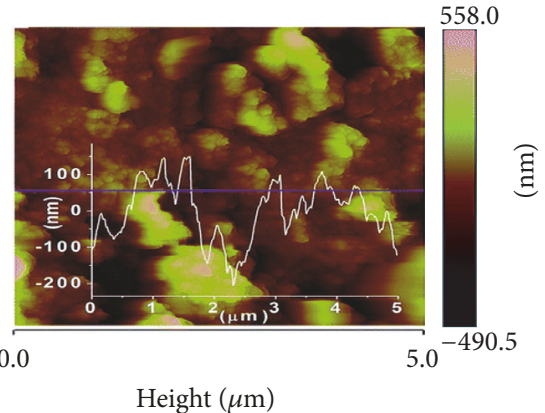

(c)

(d)

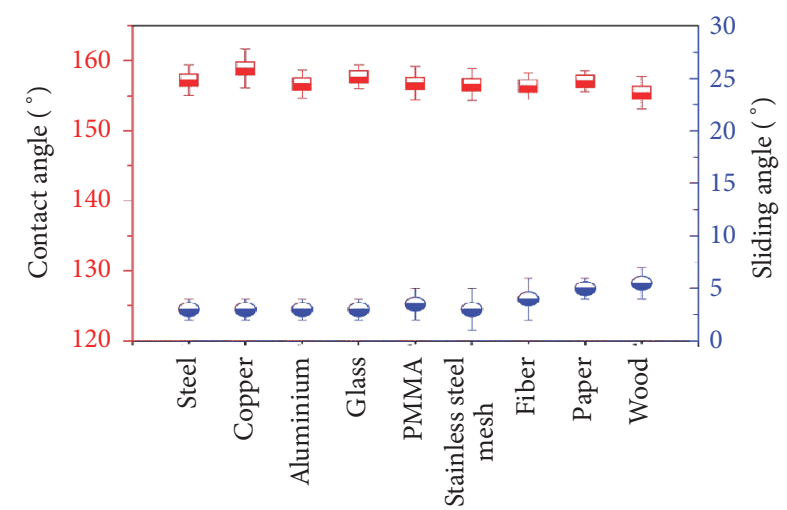

Figure 8: Synthesis of the composite superhydrophobic coating. (a) Schematic of the fabrication of the superhydrophobic coating and the possible bonding structure in the composite coating. (b) FTIR spectra of the composite coating. (c) SEM image of the composite coating on a glass slide. (d) AFM height image of the superhydrophobic surface. Inset: AFM section images of the positions marked by the line. (e) Time-resolved images of a $9.0 \mu \mathrm{L}$ water droplet spreading quickly on the composite coating within $162 \mathrm{~ms}$ (tilting angle $<3^{\circ}$ ). (f) The contact, deformation, and departure processes of a water droplet on the composite coating. ( $\mathrm{g}$ ) The water contact angles and sliding angles of the composite coating on various substrates [142].

The hydrophobicity is usually improved by increasing the surface roughness $[205,206]$ and the hydrophobic substrate requires an adequate surface roughness [207]. Therefore, techniques for making hydrophobic coatings are divided into two steps: (i) creating of a rough surface at microscale for host materials and (ii) creating nanoscale architecture surface (see Figure 9), followed by the deposition of low surface energy materials on the surface. The most common low surface materials are fluorinated and silane compounds [207]. There are many ways to increase the surface roughness: mechanical stretching, physical methods (laser, plasma), chemical etching, lithography, sol-gel processing, electrochemical reactions, or even chemical deposition in CVD vapor phase.

It should be noted that when the roughness increases, the angle of contact with water will increase or decrease depending on the surface being hydrophobic or hydrophobic [205]. Furthermore, Zhu et al. [208] argued that both the nanostructure and microstructure of the surface contribute to its hydrophobicity, as observed in the nature (the lotus leaf).

Recently, nanoparticles have been used to obtain superhydrophobic surface by turning surface roughness. In that method, the nanoparticles are applied to a fine surface or microroughness to produce a surface roughness at the submicrometer scale. Surfaces that have been sanded continue to be chemically treated or covered with a low surface energy material to increase hydrophobic effect [209211]. In another way, the nanoparticles are dispersed in the polymer solution and sprayed onto the smooth surface (such as the glass in the self-cleaning paint) [208, 212-215] as shown in Figure 8. Recently, Milionis's group [216-220] 

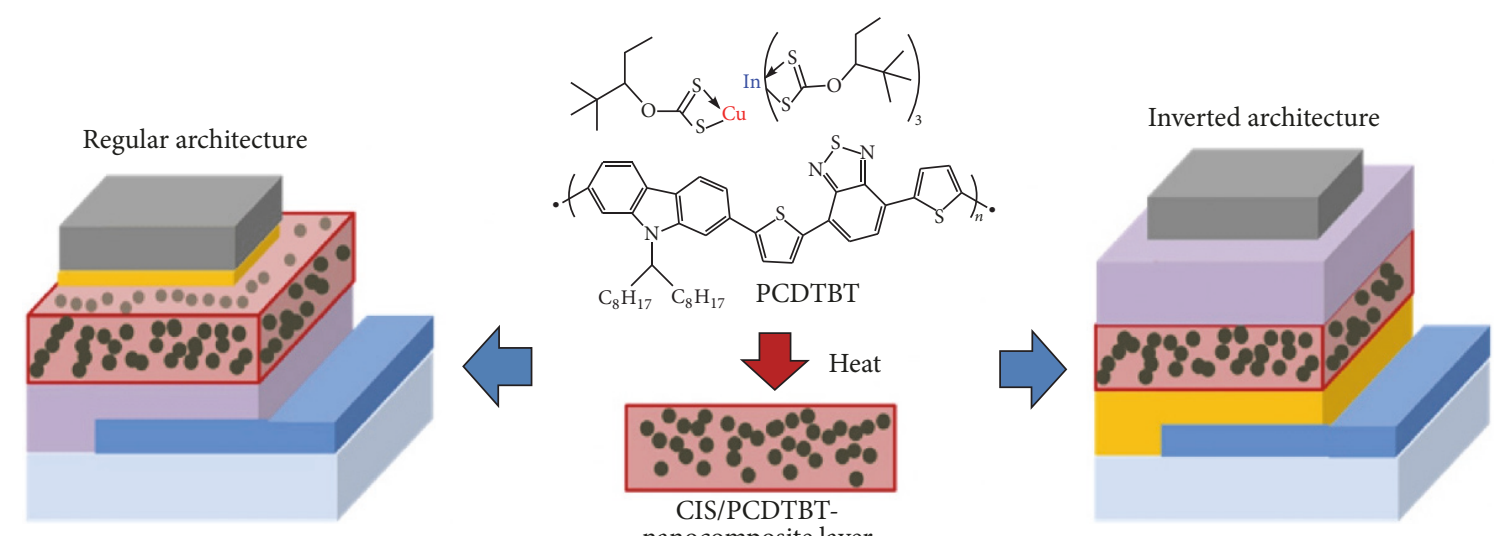

CIS/PCDTBT-
nanocomposite layer

Glass

Indium tin oxide

PEDOT:PSS (or MoO3, V2O5)

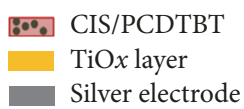

FIGURE 9: Schematic illustration of the regular and inverted device architectures and the in situ route using metal xanthates as precursors for the formation of metal sulfide nanocrystals directly in polymer matrices [143].

developed some nonwetting (superhydrophobic) coatings for specific applications, particularly for underwater-saturation or tribological purposes using nanosilica or carbon nanotube dispersed in various polymer matrices.

\section{Applications}

Table 1 presents the summary of materials, preparative methods, and applications for 4 different types of nanocomposite coatings. As can be seen in this table, the most used type of nanocomposite coatings is organic/inorganic $(\mathrm{O} / \mathrm{I})$ type (matrix/nanofiller) with various applications, such as anticorrosion, antiwear, superhydrophobic application, selfcleaning, antifouling/antibacterial application, and electronics.

In the case of anticorrosive and self-healing coatings, a specific type of nanofiller is often incorporated in their formulation, denoted as nanocontainer. Nanocontainer is of a nanosized volume and contains the active substances (inhibitor-loaded nanocontainer and healing agent-loaded nanocontainer). As designed, the nanocontainer could prevent the direct contact between these active agents and coating matrix. As the nanofillers, nanocontainers were well dispersed in the coating matrix; then they can release these healing agents under critical conditions, such as mechanical rapture, changing $\mathrm{pH}$, and light change. Nanocontainers included the halloysite clay nanotubes [221-223], zirconia nanospheres [224], nanosilica [225-227], nanoceria [228, 229], and supramolecular nanocontainers [230, 231].

\section{Conclusion and Future Trend}

We tried to trace here an overview of the nanocomposite coatings in both basic fundamental and last recent developments in design, preparation, and applications of the nanocomposite coatings. With a rapid growth rate of the nanotechnology and related fields, nanocomposites coatings today become smatter, cheaper, and more functional. The domains of application of nanocomposite coatings are thus expected to be larger in the future, dealing with drug delivery systems, anticorrosion barrier coatings, antibacterial coatings, selfscratch repair, fire retardant coatings, reflective coatings, and screen effect coatings.

The nanocomposite coating today not only serves as a protection for the materials but also plays other roles due to the presence of multifunctional nanofillers. Tow most popular examples can be cited, and they are antibacterial coatings and smart coatings which are used for sustainable energy fields. In the first case, the nanofillers based silver nanoparticles and their related products are very promising in the next decades. In the future, we will face many risks and challenges, especially energy problems, and the research on the sustainable energy conversion is expected to explode, in terms of both theory and experiment, and the nanocomposite coating will not stand out of this trend, for example, self-cleaning or "easy-to-clean" coatings, coated on building, protective substrates and on glass, can help save energy and water in facility cleaning while insulant nanocomposite coatings help to save the energy loss saving billions of dollars for maintaining homes in winter, especially in North America where the winter is cool and long (see Figure 5).

The smart coatings play also an important role in the development of new generations of sustainable energy where the multifunctional coatings can be used for the elaboration of devices in photovoltaic solar, solar thermal energy, and solar-to-fuel conversions process. 


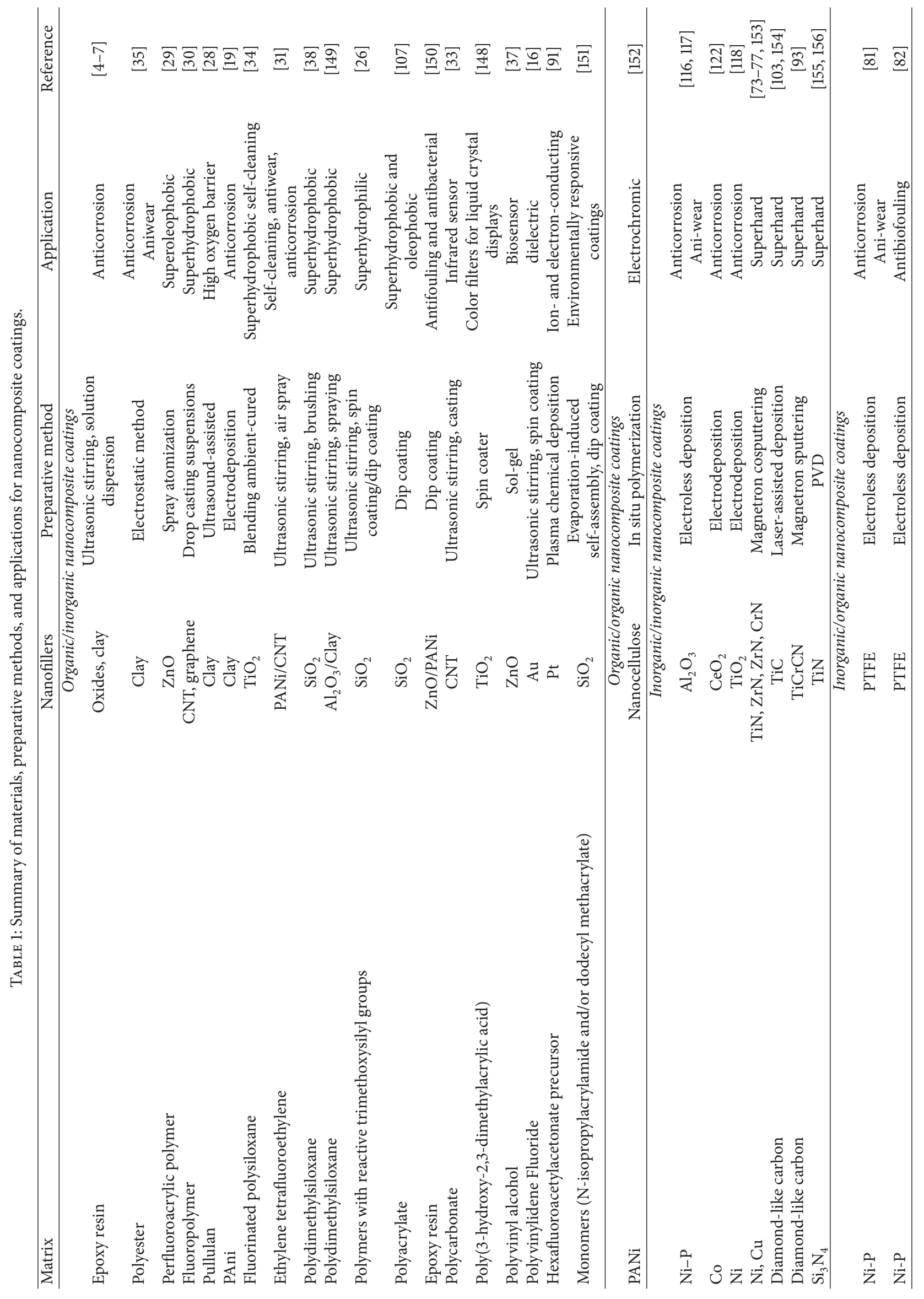




\section{Conflicts of Interest}

The authors declare that there are no conflicts of interest regarding the publication of this paper.

\section{References}

[1] D. Martinez-Martinez, "Nanocomposite Coatings," in Encyclopedia of Tribology, W. Q. Jane and C. Yip-Wah, Eds., pp. 23592364, 2013.

[2] H. Kim, H. N. Ra, M. Kim, H. G. Kim, and S. S. Kim, "Enhancement of barrier properties by wet coating of epoxyZrP nanocomposites on various inorganic layers," Progress in Organic Coatings, vol. 108, pp. 25-29, 2017.

[3] S. Pourhashem, M. R. Vaezi, A. Rashidi, and M. R. Bagherzadeh, "Exploring corrosion protection properties of solvent based epoxy-graphene oxide nanocomposite coatings on mild steel," Corrosion Science, vol. 115, pp. 78-92, 2017.

[4] X. Shi, T. A. Nguyen, Z. Suo, Y. Liu, and R. Avci, "Effect of nanoparticles on the anticorrosion and mechanical properties of epoxy coating," Surface \& Coatings Technology, vol. 204, no. 3, pp. 237-245, 2009.

[5] T. A. Nguyen, H. Nguyen, T. V. Nguyen, H. Thai, and X. Shi, "Effect of nanoparticles on the thermal and mechanical properties of epoxy coatings," Journal of Nanoscience and Nanotechnology, vol. 16, no. 9, pp. 9874-9881, 2016.

[6] P. P. Vijayan, Y. M. Hany El-Gawady, and M. A. S. A. AlMaadeed, "Halloysite Nanotube as Multifunctional Component in Epoxy Protective Coating," Industrial \& Engineering Chemistry Research, vol. 55, no. 42, pp. 11186-11192, 2016.

[7] J. Yeh, H. Huang, C. Chen, W. Su, and Y. Yu, "Siloxanemodified epoxy resin-clay nanocomposite coatings with advanced anticorrosive properties prepared by a solution dispersion approach," Surface and Coatings Technology, vol. 200, no. 8, pp. 2753-2763, 2006.

[8] A. Davis, Y. H. Yeong, A. Steele, I. S. Bayer, and E. Loth, "Superhydrophobic nanocomposite surface topography and ice adhesion," ACS Applied Materials \& Interfaces, vol. 6, no. 12, pp. 9272-9279, 2014.

[9] L.-P. Sung, J. Comer, A. M. Forster et al., "Scratch behavior of nano-alumina/polyurethane coatings," Journal of Coatings Technology and Research (JCTR), vol. 5, no. 4, pp. 419-430, 2008.

[10] L. Al-Naamani, S. Dobretsov, J. Dutta, and J. G. Burgess, "Chitosan-zinc oxide nanocomposite coatings for the prevention of marine biofouling," Chemosphere, vol. 168, pp. 408-417, 2017.

[11] Y. Tang, X. Hu, X. Zhang, D. Guo, J. Zhang, and F. Kong, "Chitosan/titanium dioxide nanocomposite coatings: Rheological behavior and surface application to cellulosic paper," Carbohydrate Polymers, vol. 151, pp. 752-759, 2016.

[12] S. Schilp, A. Rosenhahn, M. E. Pettitt et al., "Physicochemical properties of (ethylene glycol)-containing self-assembled monolayers relevant for protein and algal cell resistance," Langmuir, vol. 25, no. 17, pp. 10077-10082, 2009.

[13] S. Lowe, N. M. O’Brien-Simpson, and L. A. Connal, "Antibiofouling polymer interfaces: Poly(ethylene glycol) and other promising candidates," Polymer Chemistry, vol. 6, no. 2, pp. 198212, 2015.

[14] B. Pelaz, P. Del Pino, P. Maffre et al., "Surface Functionalization of Nanoparticles with Polyethylene Glycol: Effects on Protein Adsorption and Cellular Uptake," ACS Nano, vol. 9, no. 7, pp. 6996-7008, 2015.
[15] W.-Y. Wang, J.-Y. Shi, J.-L. Wang et al., "Preparation and characterization of PEG-g-MWCNTs/PSf nano-hybrid membranes with hydrophilicity and antifouling properties," RSC Advances, vol. 5, no. 103, pp. 84746-84753, 2015.

[16] A. Toor, H. So, and A. P. Pisano, "Improved Dielectric Properties of Polyvinylidene Fluoride Nanocomposite Embedded with Poly(vinylpyrrolidone)-Coated Gold Nanoparticles," ACS Applied Materials \& Interfaces, vol. 9, no. 7, pp. 6369-6375, 2017.

[17] U. Bogdanović, V. Vodnik, M. Mitrić et al., "Nanomaterial with high antimicrobial efficacy-copper/polyaniline nanocomposite," ACS Applied Materials \& Interfaces, vol. 7, no. 3, pp. 19551966, 2015.

[18] S. Zhang, G. Sun, Y. He, R. Fu, Y. Gu, and S. Chen, "Preparation, Characterization, and Electrochromic Properties of Nanocellulose-Based Polyaniline Nanocomposite Films," ACS Applied Materials \& Interfaces, vol. 9, no. 19, pp. 16426-16434, 2017.

[19] M. Shabani-Nooshabadi, S. M. Ghoreishi, Y. Jafari, and N. Kashanizadeh, "Electrodeposition of polyaniline-montmorrilonite nanocomposite coatings on 316L stainless steel for corrosion prevention," Journal of Polymer Research, vol. 21, no. 4, article no. 416, 2014.

[20] S. H. Yoo and C. K. Kim, "Enhancement of the meltdown temperature of a lithium ion battery separator via a nanocomposite coating," Industrial \& Engineering Chemistry Research, vol. 48, no. 22, pp. 9936-9941, 2009.

[21] S. Fujii, S. Matsuzawa, Y. Nakamura et al., "Synthesis and characterization of polypyrrole-palladium nanocomposite-coated latex particles and their use as a catalyst for suzuki coupling reaction in aqueous media," Langmuir, vol. 26, no. 9, pp. 6230$6239,2010$.

[22] A. A. Farghaly and M. M. Collinson, "Mesoporous Hybrid Polypyrrole-Silica Nanocomposite Films with a Strata-Like Structure," Langmuir, vol. 32, no. 23, pp. 5925-5936, 2016.

[23] S. Fujii, S. Matsuzawa, H. Hamasaki, Y. Nakamura, A. Bouleghlimat, and N. J. Buurma, "Polypyrrole-palladium nanocomposite coating of micrometer-sized polymer particles toward a recyclable catalyst," Langmuir, vol. 28, no. 5, pp. 2436-2447, 2012.

[24] W. Hou and Q. Wang, "UV-driven reversible switching of a polystyrene/titania nanocomposite coating between superhydrophobicity and superhydrophilicity," Langmuir, vol. 25, no. 12, pp. 6875-6879, 2009.

[25] S. He, C. Lu, and S. Zhang, "Facile and efficient route to polyimide-TiO 2 nanocomposite coating onto carbon fiber," ACS Applied Materials \& Interfaces, vol. 3, no. 12, pp. 4744-4750, 2011.

[26] E. B. Caldona, A. C. C. De Leon, P. G. Thomas, D. F. Naylor, B. B. Pajarito, and R. C. Advincula, "Superhydrophobic RubberModified Polybenzoxazine/SiO2 Nanocomposite Coating with Anticorrosion, Anti-Ice, and Superoleophilicity Properties," Industrial \& Engineering Chemistry Research, vol. 56, no. 6, pp. 1485-1497, 2017.

[27] H. Dong, P. Ye, M. Zhong, J. Pietrasik, R. Drumright, and K. Matyjaszewski, "Superhydrophilic surfaces via polymer-SiO 2 nanocomposites," Langmuir, vol. 26, no. 19, pp. 15567-15573, 2010.

[28] L. Introzzi, T. O. J. Blomfeldt, S. Trabattoni et al., "Ultrasoundassisted pullulan/montmorillonite bionanocomposite coating with high oxygen barrier properties," Langmuir, vol. 28, no. 30, pp. 11206-11214, 2012. 
[29] A. Steele, I. Bayer, and E. Loth, "Inherently superoleophobic nanocomposite coatings by Spray Atomization," Nano Letters, vol. 9, no. 1, pp. 501-505, 2009.

[30] A. Asthana, T. Maitra, R. Büchel, M. K. Tiwari, and D. Poulikakos, "Multifunctional superhydrophobic polymer/carbon nanocomposites: Graphene, carbon nanotubes, or carbon black?" ACS Applied Materials \& Interfaces, vol. 6, no. 11, pp. 8859-8867, 2014

[31] R. Yuan, S. Wu, P. Yu et al., "Superamphiphobic and Electroactive Nanocomposite toward Self-Cleaning, Antiwear, and Anticorrosion Coatings," ACS Applied Materials \& Interfaces, vol. 8, no. 19, pp. 12481-12493, 2016.

[32] K. M. Cui, M. C. Tria, R. Pernites, C. A. Binag, and R. C. Advincula, "PVK/MWNT electrodeposited conjugated polymer network nanocomposite films," ACS Applied Materials \& Interfaces, vol. 3, no. 7, pp. 2300-2308, 2011.

[33] B. Pradhan, K. Setyowati, H. Liu, D. H. Waldeck, and J. Chen, "Carbon nanotube-polymer nanocomposite infrared sensor," Nano Letters, vol. 8, no. 4, pp. 1142-1146, 2008.

[34] X. Ding, S. Zhou, G. Gu, and L. Wu, "A facile and largearea fabrication method of superhydrophobic self-cleaning fluorinated polysiloxane/TiO2 nanocomposite coatings with long-term durability," Journal of Materials Chemistry, vol. 21, no. 17, pp. 6161-6164, 2011.

[35] A. Golgoon, M. Aliofkhazraei, M. Toorani, M. Moradi, and A. S. Rouhaghdam, "Corrosion and wear properties of nanoclaypolyester nanocomposite coatings fabricated by electrostatic method," Procedia Materials Science, vol. 11, pp. 536-541, 2015.

[36] S. A. Sajjadi, M. H. Avazkonandeh-Gharavol, S. M. Zebarjad, M. Mohammadtaheri, M. Abbasi, and K. Mossaddegh, "A comparative study on the effect of type of reinforcement on the scratch behavior of a polyacrylic-based nanocomposite coating," Journal of Coatings Technology and Research (JCTR), vol. 10, no. 2, pp. 255-261, 2013.

[37] S. Habouti, C. Kunstmann-Olsen, J. D. Hoyland, H.-G. Rubahn, and M. Es-Souni, "In situ ZnO-PVA nanocomposite coated microfluidic chips for biosensing," Applied Physics A: Materials Science \& Processing, vol. 115, no. 2, pp. 645-649, 2014.

[38] D. S. Facio and M. J. Mosquera, "Simple strategy for producing superhydrophobic nanocomposite coatings in situ on a building substrate," ACS Applied Materials \& Interfaces, vol. 5, no. 15, pp. 7517-7526, 2013.

[39] K. D. Behler, A. Stravato, V. Mochalin, G. Korneva, G. Yushin, and Y. Gogotsi, "Nanodiamond-polymer composite fibers and coatings," ACS Nano, vol. 3, no. 2, pp. 363-369, 2009.

[40] A. Kaboorani, N. Auclair, B. Riedl, and V. Landry, "Mechanical properties of UV-cured cellulose nanocrystal (CNC) nanocomposite coating for wood furniture," Progress in Organic Coatings, vol. 104, pp. 91-96, 2017.

[41] V. Sergeev, S. Psakhie, P. Chubik et al., "Magnetron sputtering of Si-Al-N nanocomposite coatings on quartz for protection against impacts of high speed microparticles," Vacuum, vol. 143, pp. 454-457, 2017.

[42] A. V. Pshyk, L. E. Coy, G. Nowaczyk et al., "High temperature behavior of functional TiAlBSiN nanocomposite coatings," Surface and Coatings Technology, vol. 305, pp. 49-61, 2016.

[43] J. Profili, O. Levasseur, A. Koronai, L. Stafford, and N. Gherardi, "Deposition of nanocomposite coatings on wood using cold discharges at atmospheric pressure," Surface and Coatings Technology, 2016.

[44] L. Chen, Z. Pei, J. Xiao, J. Gong, and C. Sun, "TiAlN/Cu nanocomposite coatings deposited by filtered cathodic arc ion plating," Journal of Materials Science and Technology, vol. 33, no. 1, pp. 111-116, 2017.

[45] Q. Ma, L. Li, Y. Xu, X. Ma, Y. Xu, and H. Liu, "Effect of Ti content on the microstructure and mechanical properties of TiAlSiN nanocomposite coatings," International Journal of Refractory Metals and Hard Materials, vol. 59, pp. 114-120, 2016.

[46] C. Wang, Y. Wang, L. Wang et al., "Nanocomposite Lanthanum Zirconate Thermal Barrier Coating Deposited by Suspension Plasma Spray Process," Journal of Thermal Spray Technology, vol. 23, no. 7, pp. 1030-1036, 2014.

[47] O. Ali, R. Ahmed, N. H. Faisal et al., "Influence of Posttreatment on the Microstructural and Tribomechanical Properties of Suspension Thermally Sprayed WC-12 wt\%Co Nanocomposite Coatings," Tribology Letters, vol. 65, no. 2, 2017.

[48] M. Ramazani, F. Ashrafizadeh, and R. Mozaffarinia, "Optimization of composition in $\mathrm{Ni}(\mathrm{Al})-\mathrm{Cr} 2 \mathrm{O} 3$ based adaptive nanocomposite coatings," Journal of Thermal Spray Technology, vol. 23, no. 6, pp. 962-974, 2014.

[49] A. Bu, J. Wang, J. Zhang et al., "Corrosion behavior of $\mathrm{ZrO} 2-\mathrm{TiO} 2$ nanocomposite thin films coating on stainless steel through sol-gel method," Journal of Sol-Gel Science and Technology, vol. 81, no. 3, pp. 633-638, 2017.

[50] V. S. Anitha, S. Sujatha Lekshmy, and K. Joy, "Effect of annealing on the structural, optical, electrical and photocatalytic activity of $\mathrm{ZrO} 2-\mathrm{TiO} 2$ nanocomposite thin films prepared by sol-gel dip coating technique," Journal of Materials Science: Materials in Electronics, vol. 28, no. 14, pp. 10541-10554, 2017.

[51] M. F. Casula, A. Corrias, A. Falqui et al., "Characterization of FeCo-SiO2 nanocomposite films prepared by sol-gel dip coating," Chemistry of Materials, vol. 15, no. 11, pp. 2201-2207, 2003.

[52] S. Nagarajan, M. Mohana, P. Sudhagar et al., "Nanocomposite coatings on biomedical grade stainless steel for improved corrosion resistance and biocompatibility," ACS Applied Materials \& Interfaces, vol. 4, no. 10, pp. 5134-5141, 2012.

[53] Y. X. Xu, L. Chen, Z. Q. Liu, F. Pei, and Y. Du, "Improving thermal stability of TiSiN nanocomposite coatings by multilayered epitaxial growth," Surface and Coatings Technology, vol. 321, pp. 180-185, 2017.

[54] S. Cho, K. Takagi, H. Kwon et al., "Multi-walled carbon nanotube-reinforced copper nanocomposite coating fabricated by low-pressure cold spray process," Surface and Coatings Technology, vol. 206, no. 16, pp. 3488-3494, 2012.

[55] J. S. Kim, Y. S. Kwon, O. I. Lomovsky et al., "Cold spraying of in situ produced TiB2-Cu nanocomposite powders," Composites Science and Technology, vol. 67, no. 11-12, pp. 2292-2296, 2007.

[56] D. J. Woo, B. Sneed, F. Peerally et al., "Synthesis of nanodiamond-reinforced aluminum metal composite powders and coatings using high-energy ball milling and cold spray," Carbon, vol. 63, pp. 404-415, 2013.

[57] N. Sanpo, Saraswati, T. M. Lu, and P. Cheang, "Anti-bacterial property of cold sprayed $\mathrm{ZnO}-\mathrm{Al}$ coating," in Proceedings of the BioMedical Engineering and Informatics: New Development and the Future - 1st International Conference on BioMedical Engineering and Informatics, BMEI 2008, pp. 488-491, China, May 2008.

[58] C.-J. Li, G.-J. Yang, P.-H. Gao, J. Ma, Y.-Y. Wang, and C.-X. Li, "Characterization of nanostructured WC-Co deposited by cold spraying," Journal of Thermal Spray Technology, vol. 16, no. 5-6, pp. 1011-1020, 2007.

[59] X.-T. Luo and C.-J. Li, "Thermal stability of microstructure and hardness of cold-sprayed cBN/NiCrAl nanocomposite coating," 
Journal of Thermal Spray Technology, vol. 21, no. 3-4, pp. 578585, 2012.

[60] X.-T. Luo, G.-J. Yang, C.-J. Li, and K. Kondoh, "High strain rate induced localized amorphization in cubic $\mathrm{BN} / \mathrm{NiCrAl}$ nanocomposite through high velocity impact," Scripta Materialia, vol. 65, no. 7, pp. 581-584, 2011.

[61] X.-T. Luo and C.-J. Li, "Large sized cubic BN reinforced nanocomposite with improved abrasive wear resistance deposited by cold spray," Materials and Corrosion, vol. 83, pp. 249-256, 2015.

[62] S. W. Banovic, K. Barmak, and A. R. Marder, "Characterization of single and discretely-stepped electro-composite coatings of nickel-alumina," Journal of Materials Science, vol. 34, no. 13, pp. 3203-3211, 1999.

[63] E. García-Lecina, I. García-Urrutia, J. A. Díez et al., "Electrochemical preparation and characterization of $\mathrm{Ni} / \mathrm{SiC}$ compositionally graded multilayered coatings," Electrochimica Acta, vol. 54, no. 9, pp. 2556-2562, 2009.

[64] S. A. Lajevardi and T. Shahrabi, "Effects of pulse electrodeposition parameters on the properties of $\mathrm{Ni}-\mathrm{TiO} 2$ nanocomposite coatings," Applied Surface Science, vol. 256, no. 22, pp. 67756781, 2010.

[65] Y. S. Dong, P. H. Lin, and H. X. Wang, "Electroplating preparation of $\mathrm{Ni}-\mathrm{Al} 2 \mathrm{O} 3$ graded composite coatings using a rotating cathode," Surface and Coatings Technology, vol. 200, no. 11, pp. 3633-3636, 2006.

[66] E. Pompei, L. Magagnin, N. Lecis, and P. L. Cavallotti, "Electrodeposition of nickel-BN composite coatings," Electrochimica Acta, vol. 54, no. 9, pp. 2571-2574, 2009.

[67] S. Teruyama, N. K. Shrestha, Y. Ito, M. Iwanaga, and T. Saji, "Plating of Ni/c-BN composite film in two steps," Journal of Materials Science, vol. 39, no. 8, pp. 2941-2943, 2004.

[68] H. Gül, F. Kiliç, S. Aslan, A. Alp, and H. Akbulut, "Characteristics of electro-co-deposited Ni-Al2O3 nano-particle reinforced metal matrix composite (MMC) coatings," Wear, vol. 267, no. 5-8, pp. 976-990, 2009.

[69] H. Gül, F. Kili, M. Uysal, S. Aslan, A. Alp, and H. Akbulut, "Effect of particle concentration on the structure and tribological properties of submicron particle $\mathrm{SiC}$ reinforced Ni metal matrix composite (MMC) coatings produced by electrodeposition," Applied Surface Science, vol. 258, no. 10, pp. 4260-4267, 2012.

[70] M. E. Bahrololoom and R. Sani, "The influence of pulse plating parameters on the hardness and wear resistance of nickelalumina composite coatings," Surface and Coatings Technology, vol. 192, no. 2-3, pp. 154-163, 2005.

[71] M. R. Vaezi, S. K. Sadrnezhaad, and L. Nikzad, "Electrodeposition of $\mathrm{Ni}$-SiC nano-composite coatings and evaluation of wear and corrosion resistance and electroplating characteristics," Colloids and Surfaces A: Physicochemical and Engineering Aspects, vol. 315, no. 1-3, pp. 176-182, 2008.

[72] H. Hasannejad, T. Shahrabi, and M. Jafarian, "Synthesis and properties of high corrosion resistant $\mathrm{Ni}$-cerium oxide nanocomposite coating," Materials and Corrosion, vol. 64, no. 12, pp. 1104-1113, 2013.

[73] M. Mišina, J. Musil, and S. Kadlec, "Composite TiN-Ni thin films deposited by reactive magnetron sputter ion-plating," Surface and Coatings Technology, vol. 110, no. 3, pp. 168-172, 1998.

[74] J. Musil, P. Karvánková, and J. Kasl, "Hard and superhard Zr-NiN nanocomposite films," Surface and Coatings Technology, vol. 139, no. 1, pp. 101-109, 2001.
[75] J. Musil, P. Zeman, H. Hrubý, and P. H. Mayrhofer, “ZrN/Cu nanocomposite film - A novel superhard material," Surface and Coatings Technology, vol. 120-121, pp. 179-183, 1999.

[76] P. Zeman, R. Čerstvý, P. H. Mayrhofer, C. Mitterer, and J. Musil, "Structure and properties of hard and superhard $\mathrm{Zr}-\mathrm{Cu}-\mathrm{N}$ nanocomposite coatings," Materials Science and Engineering: A Structural Materials: Properties, Microstructure and Processing, vol. 289, no. 1-2, pp. 189-197, 2000.

[77] J. Musil, I. Leipner, and M. Kolega, "Nanocrystalline and nanocomposite $\mathrm{CrCu}$ and $\mathrm{CrCu}-\mathrm{N}$ films prepared by magnetron sputtering," Surface and Coatings Technology, vol. 115, no. 1, pp. 32-37, 1999.

[78] R. Toledano and D. Mandler, "Electrochemical codeposition of thin gold nanoparticles/sol-gel nanocomposite films," Chemistry of Materials, vol. 22, no. 13, pp. 3943-3951, 2010.

[79] J. Musil, "Hard and superhard nanocomposite coatings," Surface and Coatings Technology, vol. 125, no. 1-3, pp. 322-330, 2000.

[80] F. Wang, S. Arai, and M. Endo, "Electrochemical preparation and characterization of nickel/ultra-dispersed PTFE composite films from aqueous solution," Materials Transactions, vol. 45, no. 4, pp. 1311-1316, 2004.

[81] A. Sharma and A. K. Singh, "Electroless Ni-P-PTFE-Al2O3 dispersion nanocomposite coating for corrosion and wear resistance," Journal of Materials Engineering and Performance, vol. 23, no. 1, pp. 142-151, 2014.

[82] C. Liu and Q. Zhao, "Influence of surface-energy components of Ni-P-TiO2-PTFE nanocomposite coatings on bacterial adhesion," Langmuir, vol. 27, no. 15, pp. 9512-9519, 2011.

[83] D. Koleva, N. Boshkov, G. Raichevski, and L. Veleva, "Electrochemical corrosion behaviour and surface morphology of electrodeposited zinc, zinc-cobalt and their composite coatings," Transactions of the IMF, vol. 83, no. 4, pp. 188-193, 2005.

[84] R. Toledano, R. Shacham, D. Avnir, and D. Mandler, "Electrochemical co-deposition of sol-gel/metal thin nanocomposite films," Chemistry of Materials, vol. 20, no. 13, pp. 4276-4283, 2008.

[85] C. Sanchez, P. Belleville, M. Popall, and L. Nicole, "Hybrid materials themed issue," Chemical Society Reviews, vol. 40, pp. 453-1152, 2011.

[86] E. J. T. Pialago and C. W. Park, "Cold spray deposition characteristics of mechanically alloyed Cu-CNT composite powders," Applied Surface Science, vol. 308, pp. 63-74, 2014.

[87] S. Vepřek, M. Haussmann, S. Reiprich, L. Shizhi, and J. Dian, "Novel thermodynamically stable and oxidation resistant superhard coating materials," Surface and Coatings Technology, vol. 86-87, no. 1, pp. 394-401, 1996.

[88] D. Neerinck, P. Persoone, M. Sercu, A. Goel, D. Kester, and D. Bray, "Diamond-like nanocomposite coatings (a-C:H/a-Si:O) for tribological applications," Diamond and Related Materials, vol. 7, no. 2-5, pp. 468-471, 1998.

[89] H.-D. Männling, D. S. Patil, K. Moto, M. Jilek, and S. Veprek, "Thermal stability of superhard nanocomposite coatings consisting of immiscible nitrides," Surface and Coatings Technology, vol. 146-147, pp. 263-267, 2001.

[90] X. Hou, K.-L. Choy, N. Brun, and V. Serín, "Nanocomposite coatings codeposited with nanoparticles using aerosol-assisted chemical vapour deposition," Journal of Nanomaterials, vol. 2013, Article ID 219039, 8 pages, 2013.

[91] T. J. Wood, H. G. Andrews, R. L. Thompson, and J. P. S. Badyal, "Ion-and electron-conducting platinum-polymer nanocomposite thin films," ACS Applied Materials \& Interfaces, vol. 4, no. 12, pp. 6747-6751, 2012. 
[92] Y. T. Pei, C. Q. Chen, K. P. Shaha et al., "Microstructural control of TiC/a-C nanocomposite coatings with pulsed magnetron sputtering," Acta Materialia, vol. 56, no. 4, pp. 696-709, 2008.

[93] S. Zhang, Y. Fu, H. Du, X. T. Zeng, and Y. C. Liu, "Magnetron sputtering of nanocomposite (Ti, Cr)CN/DLC coatings," Surface and Coatings Technology, vol. 162, no. 1, pp. 42-48, 2003.

[94] E. Ribeiro, A. Malczyk, S. Carvalho et al., "Effects of ion bombardment on properties of d.c. sputtered superhard (Ti, Si, Al)N nanocomposite coatings," Surface and Coatings Technology, vol. 151-152, pp. 515-520, 2002.

[95] S. M. Aouadi, Y. Paudel, B. Luster et al., "Adaptive Mo 2N/MoS 2/Ag tribological nanocomposite coatings for aerospace applications," Tribology Letters, vol. 29, no. 2, pp. 95-103, 2008.

[96] X. Liu, C. Iamvasant, C. Liu, A. Matthews, and A. Leyland, "CrCuAgN PVD nanocomposite coatings: Effects of annealing on coating morphology and nanostructure," Applied Surface Science, vol. 392, pp. 732-746, 2017.

[97] S. H. Yao, Y. L. Su, W. H. Kao, and K. W. Cheng, "Evaluation on wear behavior of Cr-Ag-N and Cr-W-N PVD nanocomposite coatings using two different types of tribometer," Surface and Coatings Technology, vol. 201, no. 6, pp. 2520-2526, 2006.

[98] P. R. Willmott and J. R. Huber, "Pulsed laser vaporization and deposition," Reviews of Modern Physics, vol. 72, no. 1, pp. 315328, 2000.

[99] D. M. Mattox, The Foundations of Vacuum Coating Technology, Springer, Heidelberg, Germany, 2003.

[100] T. Šikola, J. Spousta, L. Dittrichová et al., "Dual ion-beam deposition of metallic thin films," Surface and Coatings Technology, vol. 84, no. 1-3, pp. 485-490, 1996.

[101] A. Meldrum, L. A. Boatner, and C. W. White, "Nanocomposites formed by ion implantation: Recent developments and future opportunities," Nuclear Instruments and Methods in Physics Research Section B: Beam Interactions with Materials and Atoms, vol. 178, no. 1-4, pp. 7-16, 2001.

[102] H. Köstenbauer, G. A. Fontalvo, C. Mitterer, and J. Keckes, "Tribological properties of TiN/Ag nanocomposite coatings," Tribology Letters, vol. 30, no. 1, pp. 53-60, 2008.

[103] A. A. Voevodin and J. S. Zabinski, "Load-adaptive crystallineamorphous nanocomposites," Journal of Materials Science, vol. 33, no. 2, pp. 319-327, 1998.

[104] H. G. Schild, "Poly(N-isopropylacrylamide): experiment, theory and application," Progress in Polymer Science, vol. 17, no. 2, pp. 163-249, 1992.

[105] F. Chen, P. Wan, H. Xu, and X. Sun, "Flexible Transparent Supercapacitors Based on Hierarchical Nanocomposite Films," ACS Applied Materials \& Interfaces, vol. 9, no. 21, pp. 1786517871, 2017.

[106] F. Villafiorita-Monteleone, C. Canale, G. Caputo et al., "Controlled swapping of nanocomposite surface wettability by multilayer photopolymerization," Langmuir, vol. 27, no. 13, pp. 85228529, 2011.

[107] S.-H. Hsu, Y.-L. Chang, Y.-C. Tu, C.-M. Tsai, and W.-F. Su, "Omniphobic low moisture permeation transparent polyacrylate/silica Nanocomposite," ACS Applied Materials \& Interfaces, vol. 5, no. 8, pp. 2991-2998, 2013.

[108] S. B. Rizvi, S. Y. Yang, M. Green, M. Keshtgar, and A. M. Seifalian, "Novel POSS-PCU Nanocomposite Material as a Biocompatible Coating for Quantum Dots," Bioconjugate Chemistry, vol. 26, no. 12, pp. 2384-2396, 2015.

[109] B. You, N. Wen, S. Zhou, L. Wu, and D. Zhao, "Facile method for fabrication of nanocomposite films with an ordered porous surface," The Journal of Physical Chemistry B, vol. 112, no. 26, pp. 7706-7712, 2008.

[110] R. H. Fernando, "Nanocomposite and nanostructured coatings: Recent advancements," ACS Symposium Series, vol. 1008, pp. 221, 2009.

[111] Z. Yang, H. Xu, Y.-L. Shi, M.-K. Li, Y. Huang, and H.-L. Li, “The fabrication and corrosion behavior of electroless Ni-P-carbon nanotube composite coatings," Materials Research Bulletin, vol. 40, no. 6, pp. 1001-1009, 2005.

[112] L. Y. Wang, J. P. Tu, W. X. Chen et al., "Friction and wear behavior of electroless Ni-based CNT composite coatings," Wear, vol. 254, no. 12, pp. 1289-1293, 2003.

[113] A. Sadeghzadeh-Attar, G. AyubiKia, and M. Ehteshamzadeh, "Improvement in tribological behavior of novel sol-enhanced electroless Ni-P-SiO2 nanocomposite coatings," Surface and Coatings Technology, vol. 307, pp. 837-848, 2016.

[114] D. Dong, X. H. Chen, W. T. Xiao, G. B. Yang, and P. Y. Zhang, "Preparation and properties of electroless Ni-P-SiO2 composite coatings," Applied Surface Science, vol. 255, no. 15, pp. 7051-7055, 2009.

[115] Y. Y. Liu, J. Yu, H. Huang et al., "Synthesis and tribological behavior of electroless Ni-P-WC nanocomposite coatings," Surface and Coatings Technology, vol. 201, no. 16-17, pp. 7246-7251, 2007.

[116] P. Makkar, R. C. Agarwala, and V. Agarwala, "Wear and corrosion characteristics of alumina dispersed $\mathrm{Ni}-\mathrm{P}$ nanocomposite coating developed by electroless technique," Journal of Materials Science, vol. 50, no. 7, pp. 2813-2823, 2015.

[117] A. Sharma and A. K. Singh, "Electroless Ni-P and Ni-P- $\mathrm{Al}_{2} \mathrm{O}_{3}$ nano-composite coatings and their corrosion and wear resistance," Journal of Materials Engineering and Performance, vol. 22, no. 1, pp. 176-183, 2013.

[118] J. Li, Y. Sun, X. Sun, and J. Qiao, "Mechanical and corrosionresistance performance of electrodeposited titania - Nickel nanocomposite coatings," Surface and Coatings Technology, vol. 192, no. 2-3, pp. 331-335, 2005.

[119] S. Dong, B. Xu, L. Du, and H. Yang, "Sand-wear resistance of brush electroplated nanocomposite coating in oil and its application to remanufacturing," Journal of Central South University of Technology, vol. 12, no. 2, pp. 176-180, 2005.

[120] A. K. Pradhan and S. Das, "Pulse Reverse Electrodeposition of $\mathrm{Cu}-\mathrm{SiC}$ Nanocomposite Coating: Effects of Surfactants and Deposition Parameters," Metallurgical and Materials Transactions A: Physical Metallurgy and Materials Science, vol. 45, no. 12, pp. 5708-5720, 2014.

[121] N. Parhizkar, A. Dolati, R. Aghababazadeh, and Z. Lalegani, "Electrochemical deposition of Ni-TiN nanocomposite coatings and the effect of sodium dodecyl sulphate surfactant on the coating properties," Bulletin of Materials Science, vol. 39, no. 4, pp. 1021-1027, 2016.

[122] L. Benea, "Electrochemical impedance spectroscopy and corrosion behavior of $\mathrm{Co} / \mathrm{CeO} 2$ nanocomposite coatings in simulating body fluid solution," Metallurgical and Materials Transactions A: Physical Metallurgy and Materials Science, vol. 44, no. 2, pp. 1114-1122, 2013.

[123] C. Zhao, Y. Yao, and L. He, "Electrodeposition and characterization of Ni-W/ZrO $\mathrm{Zn}_{2}$ nanocomposite coatings," Bulletin of Materials Science, vol. 37, no. 5, pp. 1053-1058, 2014.

[124] C. L. Weaver, J. M. Larosa, X. Luo, and X. T. Cui, "Electrically controlled drug delivery from graphene oxide nanocomposite films," ACS Nano, vol. 8, no. 2, pp. 1834-1843, 2014. 
[125] X. Pang and I. Zhitomirsky, "Electrodeposition of hydroxyapatite-silver-chitosan nanocomposite coatings," Surface and Coatings Technology, vol. 202, no. 16, pp. 3815-3821, 2008.

[126] F. F. Fang, H. J. Choi, and J. Joo, "Conducting polymer/clay nanocomposites and their applications," Journal of Nanoscience and Nanotechnology, vol. 8, no. 4, pp. 1559-1581, 2008.

[127] Y.-C. Tsai and Y.-H. Hong, "Electrochemical deposition of platinum nanoparticles in multiwalled carbon nanotube-Nafion composite for methanol electrooxidation," Journal of Solid State Electrochemistry, vol. 12, no. 10, pp. 1293-1299, 2008.

[128] P. Gajendran and R. Saraswathi, "Polyaniline-carbon nanotube composites," Pure and Applied Chemistry, vol. 80, no. 11, pp. 2377-2395, 2008.

[129] Q. Chen, L. Zhao, C. Li, and G. Shi, "Electrochemical fabrication of a memory device based on conducting polymer nanocomposites," The Journal of Physical Chemistry C, vol. 111, no. 49, pp. 18392-18396, 2007.

[130] X. Y. Wei, P. D. Prewett, and K. Jiang, "IEEE Conference on Nanotechnology," in Proceedings of the IEEE Conference on Nanotechnology, pp. 34-38, Hong Kong, China, 2007.

[131] M. Baibarac and P. Gómez-Romero, "Nanocomposites based on conducting polymers and carbon nanotubes: From fancy materials to functional applications," Journal of Nanoscience and Nanotechnology, vol. 6, no. 2, pp. 289-302, 2006.

[132] X.-L. Luo, J.-J. Xu, J.-L. Wang, and H.-Y. Chen, "Electrochemically deposited nanocomposite of chitosan and carbon nanotubes for biosensor application," Chemical Communications, no. 16, pp. 2169-2171, 2005.

[133] X. Pang and I. Zhitomirsky, "Electrodeposition of composite hydroxyapatite-chitosan films," Materials Chemistry and Physics, vol. 94, no. 2-3, pp. 245-251, 2005.

[134] S.-Y. Lu and I.-H. Lin, "Characterization of polypyrroleCdSe/CdTe nanocomposite films prepared with an all electrochemical deposition process," The Journal of Physical Chemistry B, vol. 107, no. 29, pp. 6974-6978, 2003.

[135] I. Shao, P. M. Vereecken, R. C. Cammarata, and P. C. Searson, "Kinetics of particle codeposition of nanocomposites," Journal of The Electrochemical Society, vol. 149, no. 11, pp. C610-C614, 2002.

[136] R. Peipmann, J. Thomas, and A. Bund, "Electrocodeposition of nickel-alumina nanocomposite films under the influence of static magnetic fields," Electrochimica Acta, vol. 52, no. 19, pp. 5808-5814, 2007.

[137] C. Lepiller, S. Poissonnet, P. Bonnaillie, G. Giunchi, and F. Legendre, "Electrochemical Codeposition of Copper-Strontium Hydroxide Films from Dimethylsulfoxide Solutions," Journal of The Electrochemical Society, vol. 151, no. 2, pp. D13-D23, 2004.

[138] J. Chen, P. Zhou, J. Li, and Y. Wang, "Studies on the photocatalytic performance of cuprous oxide/chitosan nanocomposites activated by visible light," Carbohydrate Polymers, vol. 72, no. 1, pp. 128-132, 2008.

[139] J.-Y. Chen, P.-J. Zhou, J.-L. Li, and S.-Q. Li, "Depositing $\mathrm{Cu} 2 \mathrm{O}$ of different morphology on chitosan nanoparticles by an electrochemical method," Carbohydrate Polymers, vol. 67, no. 4, pp. 623-629, 2007.

[140] I. Zhitomirsky, "Electrophoretic deposition of organic-inorganic nanocomposites," Journal of Materials Science, vol. 41, no. 24, pp. 8186-8195, 2006.

[141] A. Walcarius and E. Sibottier, "Electrochemically-induced deposition of amine-functionalized silica films on gold electrodes and application to $\mathrm{Cu}$ (II) detection in (hydro)alcoholic medium," Electroanalysis, vol. 17, no. 19, pp. 1716-1726, 2005.
[142] H. Ye, L. Zhu, W. Li, H. Liu, and H. Chen, "Simple spray deposition of a water-based superhydrophobic coating with high stability for flexible applications," Journal of Materials Chemistry A, vol. 5, no. 20, pp. 9882-9890, 2017.

[143] S. Dunst, T. Rath, A. Reichmann, H.-T. Chien, B. Friedel, and G. Trimmel, "A comparison of copper indium sulfidepolymer nanocomposite solar cells in inverted and regular device architecture," Synthetic Metals, vol. 222, pp. 115-123, 2016.

[144] K. Arunsunai Kumar, G. Paruthimal Kalaignan, and V. S. Muralidharan, "Direct and pulse current electrodeposition of Ni-W-TiO2 nanocomposite coatings," Ceramics International, vol. 39, no. 3, pp. 2827-2834, 2013.

[145] L. M. Chang, M. Z. An, H. F. Guo, and S. Y. Shi, "Microstructure and properties of $\mathrm{Ni}-\mathrm{Co} /$ nano-Al2O3 composite coatings by pulse reversal current electrodeposition," Applied Surface Science, vol. 253, no. 4, pp. 2132-2137, 2006.

[146] L. Wang, Y. Gao, Q. Xue, H. Liu, and T. Xu, "Graded composition and structure in nanocrystalline $\mathrm{Ni}$-Co alloys for decreasing internal stress and improving tribological properties," Journal of Physics D: Applied Physics, vol. 38, no. 8, pp. 13181324, 2005.

[147] T. J. Wood, L. J. Ward, and J. P. S. Badyal, "Super-adhesive polymer-silica nanocomposite layers," ACS Applied Materials \& Interfaces, vol. 5, no. 19, pp. 9678-9683, 2013.

[148] G. Carotenuto, Y.-S. Her, and E. Matijevié, "Preparation and characterization of nanocomposite thin films for optical devices," Industrial \& Engineering Chemistry Research, vol. 35, no. 9, pp. 2929-2932, 1996.

[149] R. Yuan, S. Wu, H. Wang et al., "Facile fabrication approach for a novel multifunctional superamphiphobic coating based on chemically grafted montmorillonite/Al2O3-polydimethylsiloxane binary nanocomposite," Journal of Polymer Research, vol. 24, no. 4, article no. 59, 2017.

[150] A. Mostafaei and F. Nasirpouri, "Preparation and characterization of a novel conducting nanocomposite blended with epoxy coating for antifouling and antibacterial applications," Journal of Coatings Technology and Research (JCTR), vol. 10, no. 5, pp. 679-694, 2013.

[151] G. Garnweitner, B. Smarsly, R. Assink, W. Ruland, E. Bond, and C. J. Brinker, "Self-assembly of an environmentally responsive polymer/silica nanocomposite," Journal of the American Chemical Society, vol. 125, no. 19, pp. 5626-5627, 2003.

[152] Y. Zhou, H. Zhang, and B. Qian, "Friction and wear properties of the co-deposited Ni-SiC nanocomposite coating," Applied Surface Science, vol. 253, no. 20, pp. 8335-8339, 2007.

[153] C. Mitterer, P. H. Mayrhofer, M. Beschliesser et al., "Microstructure and properties of nanocomposite Ti-B-N and Ti-B-C coatings," Surface and Coatings Technology, vol. 120-121, pp. 405-411, 1999.

[154] A. A. Voevodin, J. P. O’Neill, S. V. Prasad, and J. S. Zabinski, "Nanocrystalline WC and WC/a-C composite coatings produced from intersected plasma fluxes at low deposition temperatures," Journal of Vacuum Science \& Technology A, vol. 17, no. 3, pp. 986-992, 1999.

[155] S. Vepřek, “The search for novel, superhard materials," Journal of Vacuum Science \& Technology A, vol. 17, no. 5, pp. 2401-2420, 1999.

[156] S. Christiansen, M. Albrecht, H. P. Strunk, and S. Veprek, "Microstructure of novel superhard nanocrystalline-amorphous composites as analyzed by high resolution transmission electron microscopy," Journal of Vacuum Science \& Technology $B$, vol. 16, no. 1, pp. 19-22, 1998. 
[157] K. E. Tettey, M. Q. Yee, and D. Lee, "Photocatalytic and conductive MWCNT/TiO2 nanocomposite thin films," ACS Applied Materials \& Interfaces, vol. 2, no. 9, pp. 2646-2652, 2010.

[158] M. Y. Zhang, C. Ye, U. J. Erasquin, T. Huynh, C. Cai, and G. J. Cheng, "Laser engineered multilayer coating of biphasic calcium phosphate/titanium nanocomposite on metal substrates," ACS Applied Materials \& Interfaces, vol. 3, no. 2, pp. 339-350, 2011.

[159] J.-K. Yoon, G.-H. Kim, J.-M. Doh, K.-T. Hong, and D.-W. Kum, "Microstructure of in situ MoSi2/SiC nanocomposite coating formed on Mo substrate by displacement reaction," Metals and Materials International, vol. 11, no. 6, pp. 457-463, 2005.

[160] A. Yazdani and A. Zakeri, "Fabrication and Characterization of Ni-SiC Nanocomposite Coatings on Al Substrates by Ball Impact Deposition Method," Metallurgical and Materials Transactions A: Physical Metallurgy and Materials Science, vol. 48, no. 9, pp. 4180-4192, 2017.

[161] V. Miikkulainen, M. Ritala, M. Zeskelä, and R. L. Puurunen, "Crystallinity of inorganic films grown by atomic layer deposition: overview and general trends," Journal of Applied Physics, vol. 113, no. 2, Article ID 021301, 2013.

[162] J. W. Elam, J. A. Libera, T. H. Huynh, H. Feng, and M. J. Pellin, "Atomic layer deposition of aluminum oxide in mesoporous silica gel," The Journal of Physical Chemistry C, vol. 114, no. 41, pp. 17286-17292, 2010.

[163] J. W. Elam, G. Xiong, C. Y. Han et al., "Atomic layer deposition for the conformal coating of nanoporous materials," Journal of Nanomaterials, vol. 2006, Article ID 64501, 2006.

[164] C. K. Lam and K. T. Lau, "Localized elastic modulus distribution of nanoclay/epoxy composites by using nanoindentation," Composite Structures, vol. 75, no. 1-4, pp. 553-558, 2006.

[165] G. Shi, M. Q. Zhang, M. Z. Rong, B. Wetzel, and K. Friedrich, "Friction and wear of low nanometer Si3N4 filled epoxy composites," Wear, vol. 254, no. 7-8, pp. 784-796, 2003.

[166] A. Hartwig, M. Sebald, D. Pütz, and L. Aberle, "Preparation, characterisation and properties of nanocomposites based on epoxy resins - An overview," Macromolecular Symposia, vol. 221, pp. 127-135, 2005.

[167] F. Dietsche, Y. Thomann, R. Thomann, and R. Mülhaupt, "Translucent acrylic nanocomposites containing anisotropic laminated nanoparticles derived from intercalated layered silicates," Journal of Applied Polymer Science, vol. 75, no. 3, pp. 396405, 2000.

[168] A. A. Voevodin, J. P. O’Neill, and J. S. Zabinski, "Nanocomposite tribological coatings for aerospace applications," Surface and Coatings Technology, vol. 116-119, pp. 36-45, 1999.

[169] G. Ragosta, M. Abbate, P. Musto, G. Scarinzi, and L. Mascia, "Epoxy-silica particulate nanocomposites: Chemical interactions, reinforcement and fracture toughness," Polymer Journal, vol. 46, no. 23, pp. 10506-10516, 2005.

[170] U. Maitra, K. E. Prasad, U. Ramamurty, and C. N. R. Rao, "Mechanical properties of nanodiamond-reinforced polymermatrix composites," Solid State Communications, vol. 149, no. 39-40, pp. 1693-1697, 2009.

[171] S. Zhang, D. Sun, Y. Fu, and H. Du, "Recent advances of superhard nanocomposite coatings: A review," Surface and Coatings Technology, vol. 167, no. 2-3, pp. 113-119, 2003.

[172] J. Schiøtz, F. D. Di Tolla, and K. W. Jacobsen, "Softening of nanocrystalline metals at very small grain sizes," Nature, vol. 391, no. 6667, pp. 561-563, 1998.

[173] G. E. Dieter, Mechanical Metallurgy, McGraw-Hill, New York, NY, USA, 2nd edition, 1976.
[174] V. G. Gryaznov, V. A. Solov'ev, and L. I. Trusov, “The peculiarities of initial stages of deformation in nanocrystalline materials (NCMs)," Scripta Materialia, vol. 24, no. 8, pp. 1529-1534, 1990.

[175] G. Jiaqiang, L. Lei, W. Yating, S. Bin, and H. Wenbin, "Electroless Ni-P-SiC composite coatings with superfine particles," Surface and Coatings Technology, vol. 200, no. 20-21, pp. 58365842, 2006.

[176] C. Ma, F. Wu, Y. Ning, F. Xia, and Y. Liu, "Effect of heat treatment on structures and corrosion characteristics of electroless Ni-P$\mathrm{SiC}$ nanocomposite coatings," Ceramics International, vol. 40, no. 7, pp. 9279-9284, 2014.

[177] S. S. Ray and M. Okamoto, "Polymer/layered silicate nanocomposites: a review from preparation to processing," Progress in Polymer Science, vol. 28, no. 11, pp. 1539-1641, 2003.

[178] G. Tsagaropoulos and A. Eisenberg, "Dynamic mechanical study of the factors affecting the two glass transition behavior of filled polymers. Similarities and differences with random ionomers," Macromolecules, vol. 28, no. 18, pp. 6067-6077, 1995.

[179] A. M. Mayes, "Softer at the boundary," Nature Materials, vol. 4, no. 9, pp. 651-652, 2005.

[180] F. W. Starr, T. B. Schrøder, and S. C. Glotzer, "Effects of a nanoscopic filler on the structure and dynamics of a simulated polymer melt and the relationship to ultrathin films," Physical Review E: Statistical, Nonlinear, and Soft Matter Physics, vol. 64, no. 2, 2001.

[181] B. J. Ash, L. S. Schadler, and R. W. Siegel, "Glass transition behavior of alumina/polymethylmethacrylate nanocomposites," Materials Letters, vol. 55, no. 1-2, pp. 83-87, 2002.

[182] O. Zabihi, A. Hooshafza, F. Moztarzadeh, H. Payravand, A. Afshar, and R. Alizadeh, "Isothermal curing behavior and thermo-physical properties of epoxy-based thermoset nanocomposites reinforced with Fe $2 \mathrm{O} 3$ nanoparticles," Thermochimica Acta, vol. 527, pp. 190-198, 2012.

[183] L. Wang, Y. Wang, X. G. Sun, J. Q. He, Z. Y. Pan, and L. L. Yu, "Preparation and characterization of nanostructured La2Zr2O7 feedstock used for plasma spraying," Powder Technology, vol. 212, no. 1, pp. 267-277, 2011.

[184] L. Wang, Y. Wang, X. G. Sun, J. Q. He, Z. Y. Pan, and C. H. Wang, "Thermal shock behavior of $8 \mathrm{YSZ}$ and double-ceramiclayer La 2Zr $2 \mathrm{O} 7 / 8 \mathrm{YSZ}$ thermal barrier coatings fabricated by atmospheric plasma spraying," Ceramics International, vol. 38, no. 5, pp. 3595-3606, 2012.

[185] M. Q. Zhang, M. Z. Rong, S. L. Yu, B. Wetzel, and K. Friedrich, "Effect of particle surface treatment on the tribological performance of epoxy based nanocomposites," Wear, vol. 253, no. 9-10, pp. 1086-1093, 2002.

[186] T. Rabizadeh and S. R. Allahkaram, "Corrosion resistance enhancement of Ni-P electroless coatings by incorporation of nano-SiO 2 particles," Materials and Corrosion, vol. 32, no. 1, pp. 133-138, 2011.

[187] H. Ashassi-Sorkhabi, H. Aminikia, and R. Bagheri, "Electroless Deposition of Ni-Cu-P Coatings Containing Nano- $\mathrm{Al}_{2} \mathrm{O}_{3}$ Particles and Study of Its Corrosion Protective Behaviour in $0.5 \mathrm{M}$ $\mathrm{H}_{2} \mathrm{SO}_{4}$," International Journal of Corrosion, vol. 2014, Article ID 391502, 9 pages, 2014.

[188] H. M. Jin, S. H. Jiang, and L. N. Zhang, "Microstructure and corrosion behavior of electroless deposited Ni-P/CeO2 coating," Chinese Chemical Letters, vol. 19, no. 11, pp. 1367-1370, 2008.

[189] H. Li, Y. He, T. He et al., "Ni-W/BN(h) electrodeposited nanocomposite coating with functionally graded microstructure," Journal of Alloys and Compounds, vol. 704, pp. 32-43, 2017. 
[190] H. Ogihara, H. Wang, and T. Saji, "Electrodeposition of Ni$\mathrm{B} / \mathrm{SiC}$ composite films with high hardness and wear resistance," Applied Surface Science, vol. 296, pp. 108-113, 2014.

[191] Y. Yang and Y. F. Cheng, "Mechanistic aspects of electrodeposition of Ni-Co-SiC compositenano-coating on carbon steel," Electrochimica Acta, vol. 109, pp. 638-644, 2013.

[192] Y. Xu, Y. Zhu, G. Xiao, and C. Ma, "Application of artificial neural networks to predict corrosion behavior of $\mathrm{Ni}$-SiC composite coatings deposited by ultrasonic electrodeposition," Ceramics International, vol. 40, no. 4, pp. 5425-5430, 2014.

[193] A. Zoikis-Karathanasis, E. A. Pavlatou, and N. Spyrellis, "Pulse electrodeposition of Ni-P matrix composite coatings reinforced by SiC particles," Journal of Alloys and Compounds, vol. 494, no. 1-2, pp. 396-403, 2010.

[194] X. Wei, G. Zhang, and L. Wang, "Metal-reservoir carbon-based nanocomposite coating for green tribology," Tribology Letters, vol. 59, no. 2, article no. 34, 2015.

[195] X. Wei, G. Zhang, and L. Wang, "Adsorption and tribochemistry aspects of nc-(W,Ti)C/a-C(Al) film with oil addition under boundary lubrication," Tribology International, vol. 80, pp. 7-13, 2014.

[196] M. Manca, A. Cannavale, L. De Marco, A. S. Aricò, R. Cingolani, and G. Gigli, "Durable superhydrophobic and antireflective surfaces by trimethylsilanized silica nanoparticles-based sol-gel processing," Langmuir, vol. 25, no. 11, pp. 6357-6362, 2009.

[197] T. He, Y. Wang, Y. Zhang, Q. lv, T. Xu, and T. Liu, "Superhydrophobic surface treatment as corrosion protection for aluminum in seawater," Corrosion Science, vol. 51, no. 8, pp. 1757-1761, 2009.

[198] M. Qu, B. Zhang, S. Song, L. Chen, J. Zhang, and X. Cao, "Fabrication of superhydrophobic surfaces on engineering materials by a solution-immersion process," Advanced Functional Materials, vol. 17, no. 4, pp. 593-596, 2007.

[199] Z. Lu, P. Wang, and D. Zhang, "Super-hydrophobic film fabricated on aluminium surface as a barrier to atmospheric corrosion in a marine environment," Corrosion Science, vol. 91, pp. 287-296, 2015.

[200] T. Kako, A. Nakajima, H. Irie et al., "Adhesion and sliding of wet snow on a super-hydrophobic surface with hydrophilic channels," Journal of Materials Science, vol. 39, no. 2, pp. 547$555,2004$.

[201] D. K. Sarkar and M. Farzaneh, "Superhydrophobic coatings with reduced ice adhesion," Journal of Adhesion Science and Technology, vol. 23, no. 9, pp. 1215-1237, 2009.

[202] S. A. Kulinich and M. Farzaneh, "Ice adhesion on superhydrophobic surfaces," Applied Surface Science, vol. 255, no. 18, pp. 8153-8157, 2009.

[203] S. A. Kulinich and M. Farzaneh, "How wetting hysteresis influences ice adhesion strength on superhydrophobic surfaces," Langmuir, vol. 25, no. 16, pp. 8854-8856, 2009.

[204] J. Li, Y. Zhao, J. Hu, L. Shu, and X. Shi, "Anti-icing performance of a superhydrophobic PDMS/modified nano-silica hybrid coating for insulators," Journal of Adhesion Science and Technology, vol. 26, no. 4-5, pp. 665-679, 2012.

[205] H. M. Shang, Y. Wang, K. Takahashi, G. Z. Cao, D. Li, and Y. N. Xia, "Nanostructured superhydrophobic surfaces," Journal of Materials Science, vol. 40, no. 13, pp. 3587-3591, 2005.

[206] R. N. Wenzel, "Surface roughness and contact angle," The Journal of Physical \& Colloid Chemistry, vol. 53, no. 9, pp. 14661467, 1949.
[207] M. Ma and R. Hill M, "Superhydrophobic surfaces," Current Opinion in Colloid \& Interface Science, vol. 11, no. 4, pp. 193-202, 2006.

[208] M. Zhu, W. Zuo, H. Yu, W. Yang, and Y. Chen, "Superhydrophobic surface directly created by electrospinning based on hydrophilic material," Journal of Materials Science, vol. 41, no. 12, pp. 3793-3797, 2006.

[209] L. Zhai, F. C. Cebeci, R. E. Cohen, and M. F. Rubner, "Stable superhydrophobic coatings from polyelectrolyte multilayers," Nano Letters, vol. 4, no. 7, pp. 1349-1353, 2004.

[210] J. Bravo, L. Zhai, Z. Wu, R. E. Cohen, and M. F. Rubner, "Transparent superhydrophobic films based on silica nanoparticles," Langmuir, vol. 23, no. 13, pp. 7293-7298, 2007.

[211] H.-M. Bok, T.-Y. Shin, and S. Park, "Designer binary nanostructures toward water slipping superhydrophobic surfaces," Chemistry of Materials, vol. 20, no. 6, pp. 2247-2251, 2008.

[212] C.-T. Hsieh, J.-M. Chen, R.-R. Kuo, T.-S. Lin, and C.-F. Wu, "Influence of surface roughness on water- And oil-repellent surfaces coated with nanoparticles," Applied Surface Science, vol. 240, no. 1-4, pp. 318-326, 2005.

[213] E. Chibowski, L. Hołysz, K. Terpilowski, and M. Jurak, "Investigation of super-hydrophobic effect of PMMA layers with different fillers deposited on glass support," Colloids and Surfaces A: Physicochemical and Engineering Aspects, vol. 291, no. 1-3, pp. 181-190, 2006.

[214] M. Y. Yüce, A. L. Demirel, and F. Menzel, “Tuning the surface hydrophobicity of polymer/nanoparticle composite films in the wenzel regime by composition," Langmuir, vol. 21, no. 11, pp. 5073-5078, 2005.

[215] M. Y. Yüce and A. L. Demirel, "The effect of nanoparticles on the surface hydrophobicity of polystyrene," The European Physical Journal B, vol. 64, no. 3-4, pp. 493-497, 2008.

[216] A. Milionis, K. Dang, M. Prato, E. Loth, and I. S. Bayer, "Liquid repellent nanocomposites obtained from one-step water-based spray," Journal of Materials Chemistry A, vol. 3, no. 24, pp. 12880-12889, 2015.

[217] A. Milionis, R. Ruffilli, and I. S. Bayer, "Superhydrophobic nanocomposites from biodegradable thermoplastic starch composites (Mater-Bi ${ }^{\circledR}$ ), hydrophobic nano-silica and lycopodium spores," RSC Advances, vol. 4, no. 65, pp. 34395-34404, 2014.

[218] J. Cheek, A. Steele, I. S. Bayer, and E. Loth, "Underwater saturation resistance and electrolytic functionality for superhydrophobic nanocomposites," Colloid and Polymer Science, vol. 291, no. 8, pp. 2013-2016, 2013.

[219] I. S. Bayer, A. Steele, and E. Loth, "Superhydrophobic and electroconductive carbon nanotube-fluorinated acrylic copolymer nanocomposites from emulsions," Chemical Engineering Journal, vol. 221, pp. 522-530, 2013.

[220] P. Cataldi, I. S. Bayer, R. Cingolani, S. Marras, R. Chellali, and A. Athanassiou, "A Thermochromic Superhydrophobic Surface," Scientific Reports, vol. 6, Article ID 27984, 2016.

[221] D. G. Shchukin, S. V. Lamaka, K. A. Yasakau, M. L. Zheludkevich, M. G. S. Ferreira, and H. Möhwald, "Active anticorrosion coatings with halloysite nanocontainers," The Journal of Physical Chemistry C, vol. 112, no. 4, pp. 958-964, 2008.

[222] S. Manasa, A. Jyothirmayi, T. Siva et al., "Nanoclay-based selfhealing, corrosion protection coatings on aluminum, A356.0 and AZ91 substrates," Journal of Coatings Technology and Research (JCTR), vol. 14, no. 5, pp. 1195-1208, 2017.

[223] E. Shchukina, D. Grigoriev, T. Sviridova, and D. Shchukin, "Comparative study of the effect of halloysite nanocontainers 
on autonomic corrosion protection of polyepoxy coatings on steel by salt-spray tests," Progress in Organic Coatings, vol. 108, pp. 84-89, 2017.

[224] A. Chenan, S. Ramya, R. P. George, and U. Kamachi Mudali, "Hollow mesoporous zirconia nanocontainers for storing and controlled releasing of corrosion inhibitors," Ceramics International, vol. 40, no. 7, pp. 10457-10463, 2014.

[225] A. Keyvani, M. Yeganeh, and H. Rezaeyan, "Application of mesoporous silica nanocontainers as an intelligent host of molybdate corrosion inhibitor embedded in the epoxy coated steel," Progress in Natural Science: Materials International, vol. 27, no. 2, pp. 261-267, 2017.

[226] C. Zea, R. Barranco-García, J. Alcántara, B. Chico, M. Morcillo, and D. de la Fuente, "Hollow mesoporous silica nanoparticles loaded with phosphomolybdate as smart anticorrosive pigment," Journal of Coatings Technology and Research (JCTR), vol. 14, no. 4, pp. 869-878, 2017.

[227] M. Yeganeh and A. Keyvani, "The effect of mesoporous silica nanocontainers incorporation on the corrosion behavior of scratched polymer coatings," Progress in Organic Coatings, vol. 90, pp. 296-303, 2016.

[228] I. Kartsonakis, I. Daniilidis, and G. Kordas, "Encapsulation of the corrosion inhibitor 8-hydroxyquinoline into ceria nanocontainers," Journal of Sol-Gel Science and Technology, vol. 48, no. 1-2, pp. 24-31, 2008.

[229] I. A. Kartsonakis, E. P. Koumoulos, A. C. Balaskas, G. S. Pappas, C. A. Charitidis, and G. C. Kordas, "Hybrid organic-inorganic multilayer coatings including nanocontainers for corrosion protection of metal alloys," Corrosion Science, vol. 57, pp. 56-66, 2012.

[230] S. Amiri and A. Rahimi, "Synthesis and characterization of supramolecular corrosion inhibitor nanocontainers for anticorrosion hybrid nanocomposite coatings," Journal of Polymer Research, vol. 22, no. 5, pp. 1-9, 2015.

[231] T. Chen and J. Fu, "An intelligent anticorrosion coating based on pH-responsive supramolecular nanocontainers," Nanotechnology, vol. 23, no. 50, Article ID 505705, 2012. 


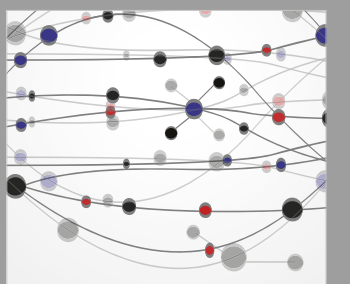

The Scientific World Journal
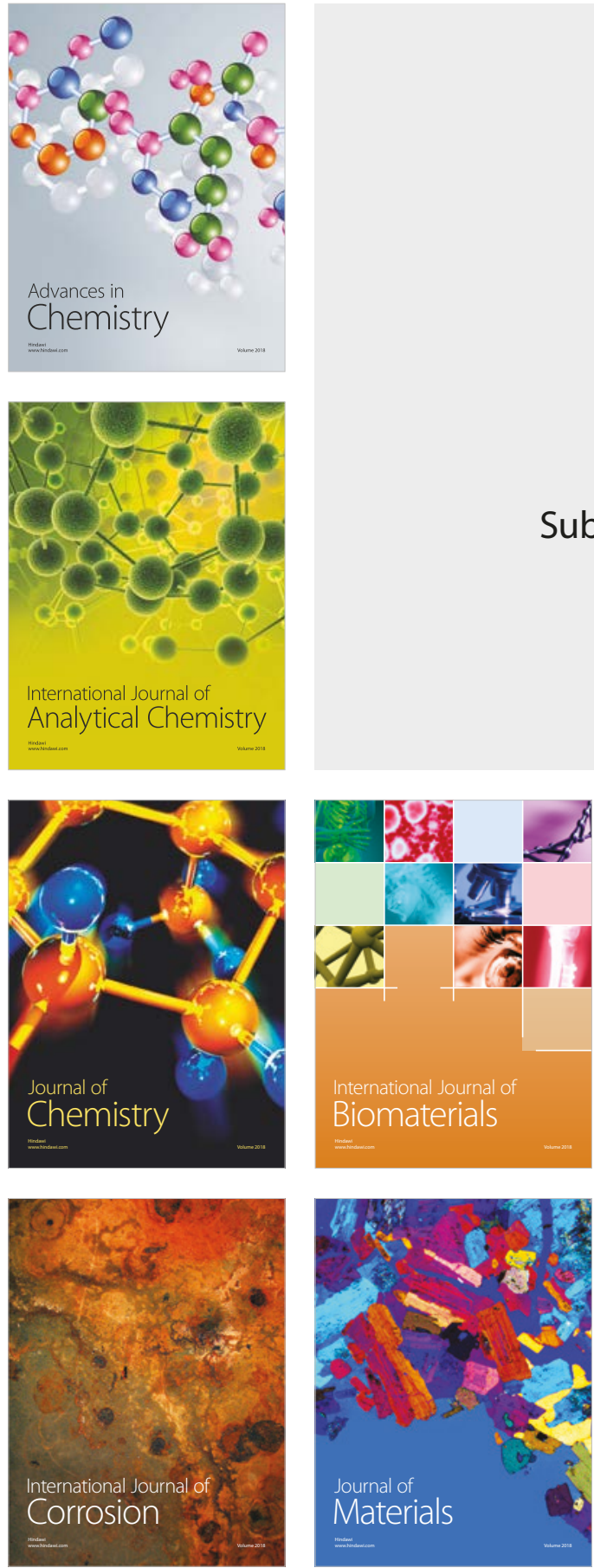

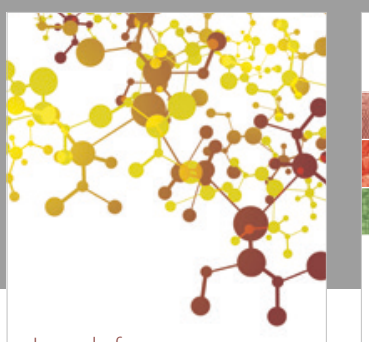

Journal of

Applied Chemistry
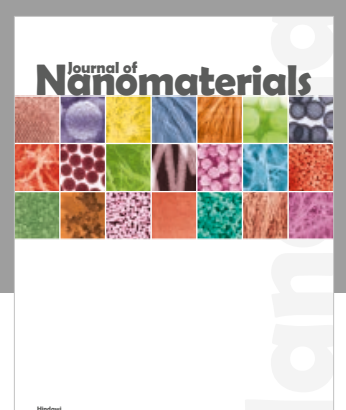

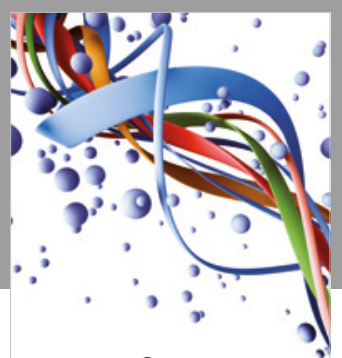

Scientifica

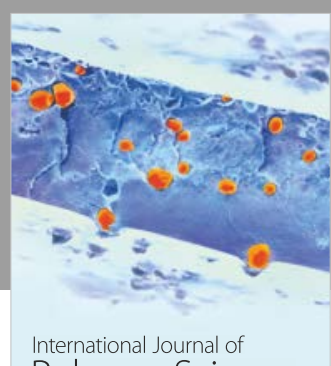

Polymer Science

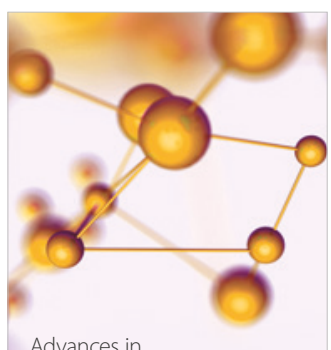

Physical Chemistry
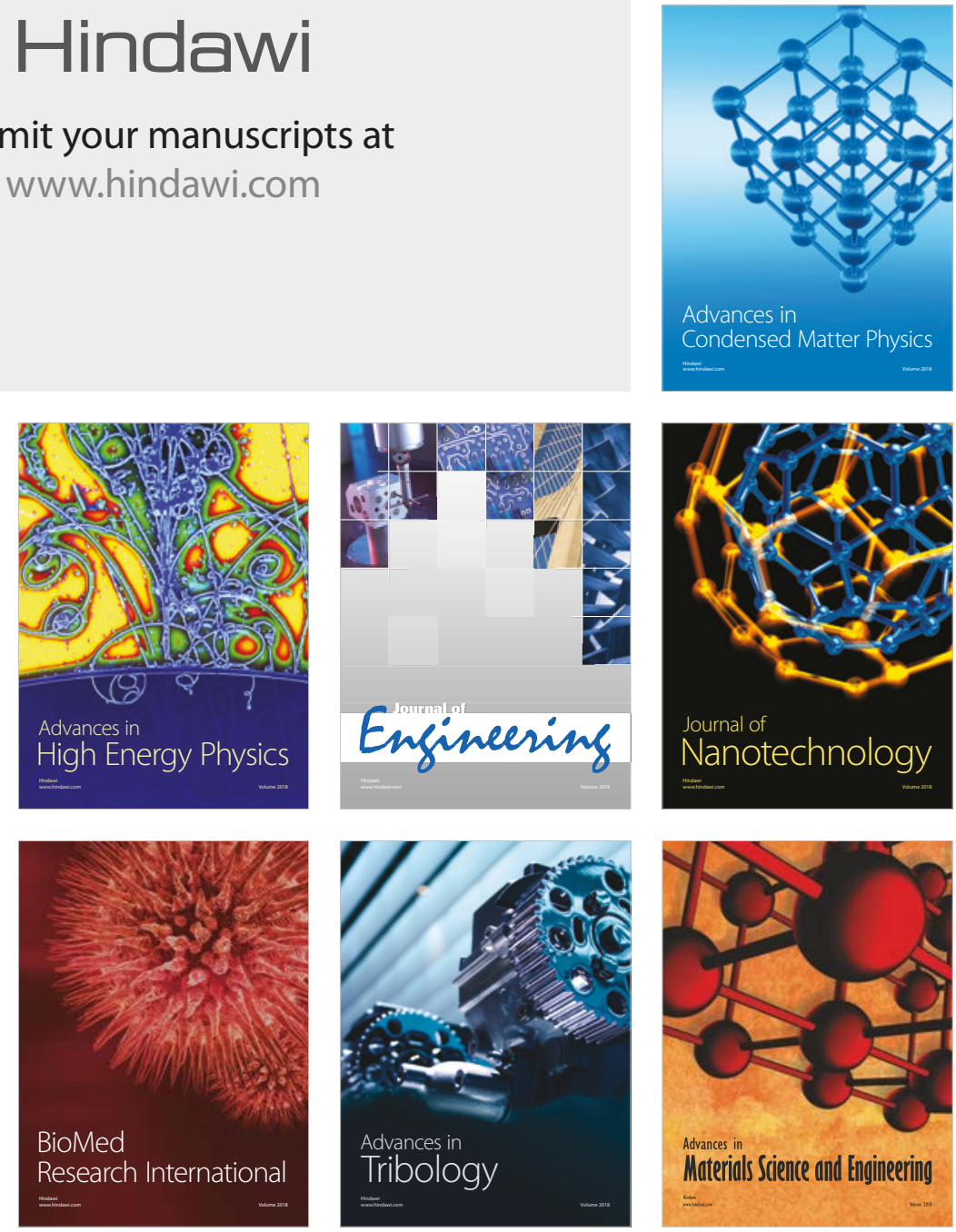